\title{
A Review of Nonbiodegradable and Biodegradable Composites for Food Packaging Application
}

\author{
Aina Aqila Arman Alim ${ }^{1},{ }^{1}$ Siti Salwa Mohammad Shirajuddin, ${ }^{2}$ \\ and Farah Hannan Anuar $\mathbb{D}^{1,3}$ \\ ${ }^{1}$ Department of Chemical Sciences, Universiti Kebangsaan Malaysia, UKM Bangi 43600, Selangor, Malaysia \\ ${ }^{2}$ Radiation Processing Technology, Malaysian Nuclear Agency, Kajang 43000, Selangor, Malaysia \\ ${ }^{3}$ Polymer Research Centre (PORCE), Universiti Kebangsaan Malaysia, UKM Bangi 43600, Selangor, Malaysia \\ Correspondence should be addressed to Farah Hannan Anuar; farahhannan@ukm.edu.my
}

Received 28 September 2021; Revised 21 December 2021; Accepted 20 January 2022; Published 16 February 2022

Academic Editor: Shahid Hussain

Copyright ( $) 2022$ Aina Aqila Arman Alim et al. This is an open access article distributed under the Creative Commons Attribution License, which permits unrestricted use, distribution, and reproduction in any medium, provided the original work is properly cited.

\begin{abstract}
The dependency on nonbiodegradable-based food packaging, increase in population growth, and persistent environmental problems are some of the driving forces in considering the development of biodegradable food packaging. This effort of green packaging has the potential to solve issues on plastic wastes through the combination of biodegradable composite-based food packaging with plant extracts, nanomaterials, or other types of polymer. Modified biodegradable materials have provided numerous alternatives for producing green packaging with mechanical strength, thermal stability, and barrier performance that are comparable to the conventional food packaging. To the best of our knowledge, the performance of nonbiodegradable and biodegradable composites as food packaging in terms of the above properties has not yet been reviewed. In this context, the capability of biodegradable polymers to substitute the nonbiodegradable polymers was emphasized to enhance the packaging biodegradation while retaining the mechanical strength, thermal stability, barrier properties, and antioxidant and antimicrobial or antibacterial activity. These are the ultimate goal in the food industry. This review will impart useful information on the properties of food packaging developed from different polymers and future outlook toward the development of green food packaging.
\end{abstract}

\section{Introduction}

In line with country development and population growth, plastic pollution is an inevitable global issue caused by plastic usage in various daily activities. Plastic represents a material that is low cost, lightweight, and bio-inert with high mechanical properties $[1,2]$. However, the production of numerous types of plastic has led to the overaccumulation of waste after use [3]. Malaysia has recorded the highest annual per capita plastic packaging consumption with $16.80 \mathrm{~kg}$ per person on top of other countries, such as Thailand, Vietnam, China, Indonesia, and the Philippines [4]. Consequently, the accumulation of mismanaged plastic wastes in the environment will directly affect human health, soil pollution, water contamination, animal life, and economic losses [5-7]. For instance, the accumulation of $\sim 2$ tons of plastic per day in one of the Indonesian coastal areas is shown in Figure 1 [8]. The globally generated pandemic-associated plastic wastes from different sources (medical waste, personal protection equipment, and online packaging) have surpassed 8 million tons, resulting in the discharge of more than 25,000 tons to the ocean $[9,10]$.

To date, there are three common routes for removing plastic wastes, which are mechanical recycling, energy recovery, and landfill. Most consumers might think that recycling is the most environmentally friendly approach to manage plastic wastes. However, the multilayers of different polymers result in some complications, whereby they should be separated according to the same kind, resulting in only less than $14 \%$ of the plastic wastes that are actually accepted for recycling $[11,12]$. The usage of single-use plastics such as straws, coffee stirrers, and water bottles also affects the 


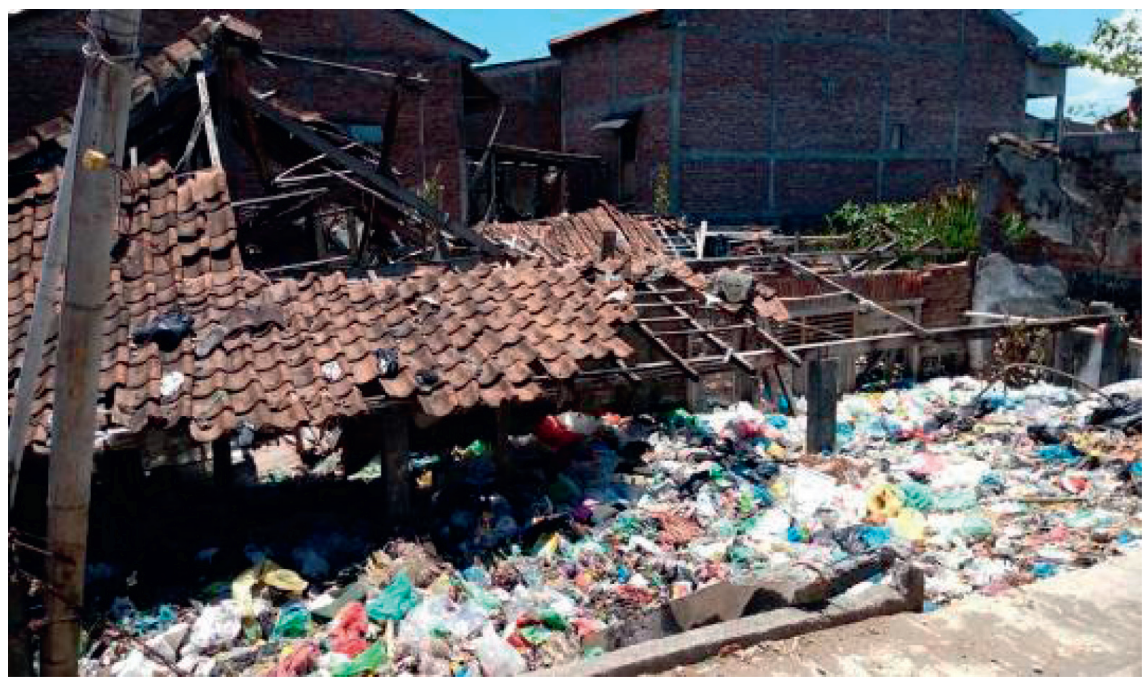

Figure 1: Plastic waste accumulation in Tambak Lorok coastal area, Semarang, Indonesia [8].

environment [13]. The release of toxic gases during incineration and reduction in plastic waste of up to $95 \%$ could affect the environment, human health, and energy recovery $[14,15]$. Rujnic-Sokele and Pilipovi also revealed that waste disposal areas may exhibit a particular issue in the release of methane gas because a gas collection system is lacking, leading to several thousands of illegal dumps [11]. In 2016, from a total of 25.80 metric tons of plastic wastes in Europe only $29 \%$ were recycled, whereas more than $30.80 \%$ of the wastes were landfilled [16].

Generally, plastic materials can be found in construction $(20.10 \%)$, automotive $(8.60 \%)$, electrical and electronic (5.70\%), and agriculture and other sectors (26.10\%), whereby the greatest market sector is monopolized by packaging supply (39.50\%) [17]. The food industry is a primary sector, which contributes to the accumulation of plastic packaging. The international plastic industry has escalated to 322 million tons [18]. In 2015, a total of 49 million tons of plastic were utilized as food packaging and the disposal of used packages had caused a great impact on the environment. It is generally noted that the primary aspects of packaging are to secure food from exterior environmental damage (physical, chemical, and biological), maintain quality, and increase the service life in addition to food safety. Besides, packaging also facilitates the storage and transportation of products $[19,20]$. Therefore, packaging materials were examined not only with respect to their performances in terms of mechanical strength, thermal stability, barrier properties, and freshness of packed food, but also with respect to their biodegradable and sustainable resources to replace nonbiodegradable materials [21, 22].

Studies on nonbiodegradable and biodegradable composites for food packaging application are reported here. The polymers covered in this review were polyethylene, polypropylene, polyvinyl chloride, polystyrene, and polyethylene terephthalate for nonbiodegradable-based composites. Meanwhile, cellulose, gelatin, polylactic acid, polyhydroxybutyrate, polycaprolactone, and polybutylene succinate were reviewed for biodegradable-based composites.
The properties for both composites were highlighted based on its biodegradation, mechanical strength, thermal stability, barrier performance, and antioxidant and antimicrobial or antibacterial activity. Figure 2 shows the workflow overview of this study.

Superior mechanical and thermal properties, high barrier performance, good antimicrobial and antioxidant activity, and improved biodegradation (Figure 3) [23-27] are the key features that attract the demand for commercial packaging materials [28]. Mechanical properties determine the film stability to prevent premature failure or cracking during handling, storage, and transport [29]. Tensile strength (TS) can be defined as the maximum amount of tensile stress resisted by a material before breaking. The strain to break a material represents the elongation at break (EB), while modulus refers to the slope of linear elastic deformation of a stress-strain curve created during the tests conducted on a sample [30]. To obtain composites with excellent mechanical properties, it is of utmost importance to study their morphology [31]. Besides, the thermogravimetric analysis measures the weight change in a sample during heating. This technique enables a good insight into the specific thermal behavior of polymeric materials, which is related to their composition and structure of material due to chemical reactions or physical changes [29, 32]. Barrier properties determine the capacity of film to minimize moisture transfer and water permeability from internal or external environment through the food packaging [33]. It is necessary to keep the moisture levels as low as possible to prolong the shelf life of food [28]. Low barrier oxygen permeability presents a key factor for oxidation reaction, which contributes to food quality degradation, whereas the presence of carbon dioxide gas may prevent bacterial and fungal growth on food products [34]. Oxidation is one of the primary reasons for food spoilage and nutritional loss, which occur during food processing and storage. The incorporation of antioxidant or antimicrobial agents into or as coating for the food packaging materials is an innovation to substitute the traditional food packaging as compared to the use of 


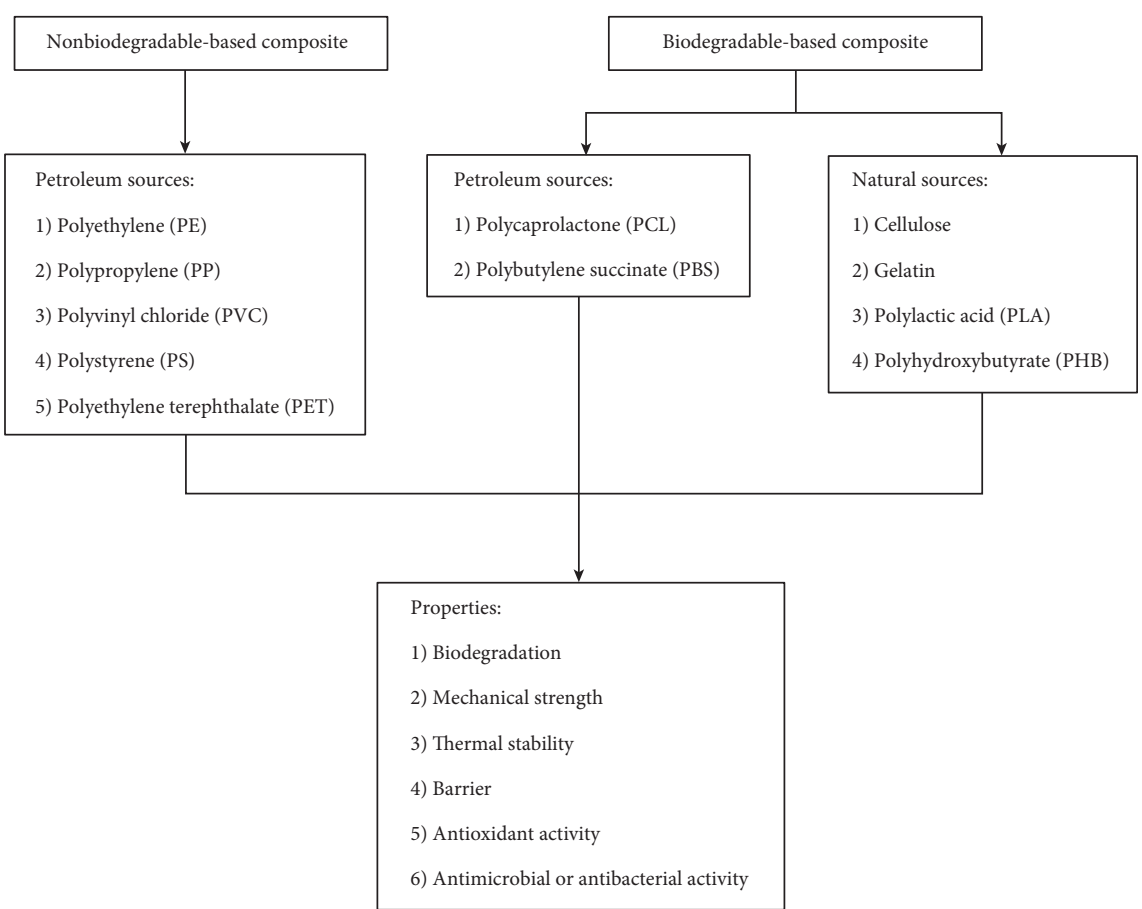

Figure 2: Workflow overview of this study.
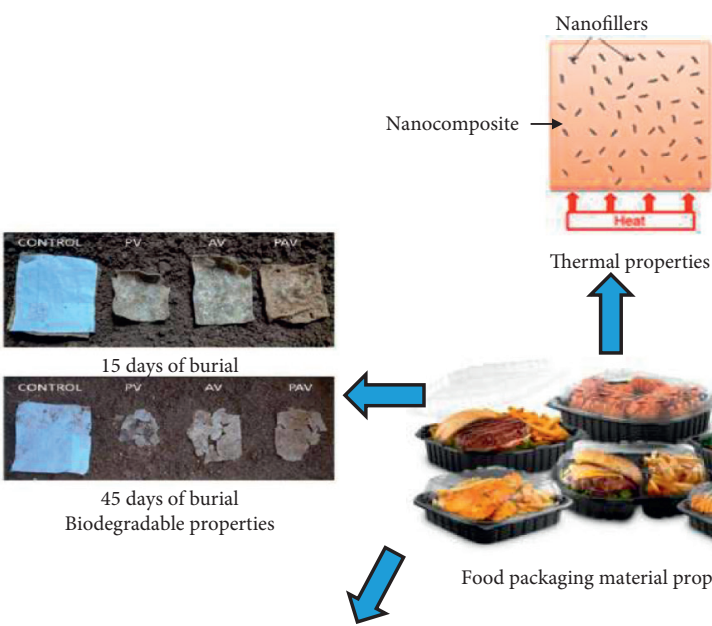

45 days of burial Biodegradable properties
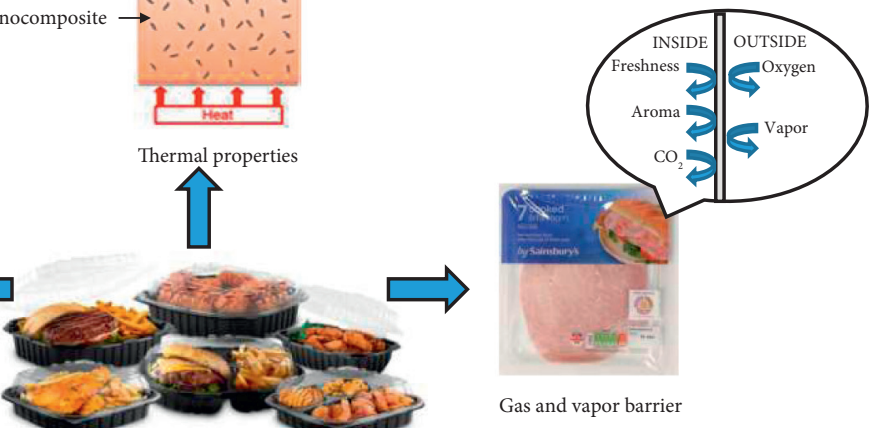

Gas and vapor barrier

Food packaging material properties

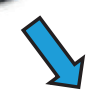

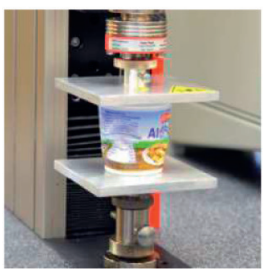

Mechanical properties

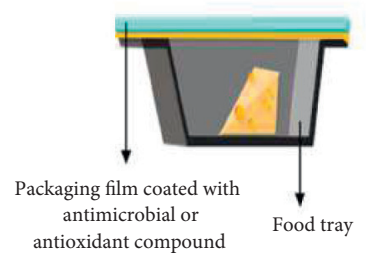

Antimicrobial or antioxidant properties

Figure 3: Properties of food packaging materials [23-27].

agents in the food itself $[35,36]$. Packaged fresh food with high moisture content will lead to the growth of microorganisms, and thus, antimicrobial food packaging has received great attention in developing food packaging to overcome this problem [37]. The most widely used antimicrobial nanoparticles are nanoclays, silver nanoparticles, zinc oxide, and functional biopolymers such as chitosan
[38]. Lastly, the biodegradable property of a material is defined as its ability to be decomposed due to the action of microorganisms [39]. The use of biodegradable polymeric materials over nonbiodegradable materials is a good solution in preserving the fossil resources and reducing environmental pollution [40]. During the biodegradation process (Figure 4), polymers are broken down into smaller 


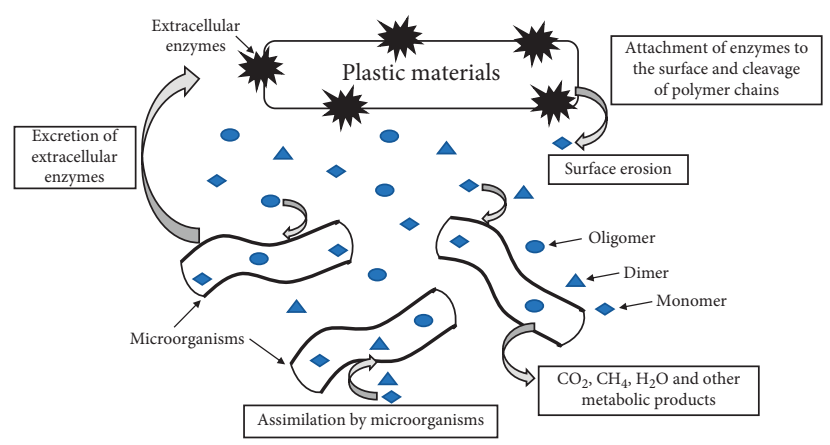

FIgURE 4: Mechanism of plastic biodegradation process.

molecular fragments (oligomers, dimers, and monomers) in the presence of specific enzymes secreted by microorganisms, which are ultimately converted into biodecomposed products, such as water and carbon dioxide (aerobic conditions) and biomass, methane, and hydrocarbons (anaerobic conditions) $[17,39]$. Biodegradation can be carried out by various techniques such as aerobic biodegradation (soil and composting environment) and anaerobic biodegradation (enzymatic hydrolysis) [41-44]. The environmental conditions, test conditions, and type of polymer affect the rate of decomposition. A comprehensive review of these techniques has been done previously [45-47].

Biodegradable polymers can be classified into three groups: I) polymers derived from biomass, proteins, and polysaccharides; II) synthetic polymers derived from biomass-derived or oil-based monomers, polybutylene succinate (PBS), and polycaprolactone (PCL); and III) polymers originated from microorganisms, polyhydroxyalkanoates (PHAs), or polyhydroxybutyrate (PHB) [48]. The comparison between nonbiodegradable and biodegradable materials in terms of degradation rate is listed in Table 1 [49-76]. It was pointed out that the degradation rate of nonbiodegradable polymer was lower than that of biodegradable polymer. In fact, the compact and long carbon chains of synthetic plastics were difficult to degrade by microorganisms [14]. Generally, the biodegradability of a polymer could help the biodegradation process of the base material [77]. The incorporation of biomass filler could enhance the degradation rate of both polymers due to the hydrophilic nature of the filler, which facilitated the microorganism attack on the surface of composite. It is known that microorganisms will consume the filler and cause a fracture in the polymer chain, which results in a higher degradation rate of modified composite with respect to the neat [78]. In a soil degradation test, it was found that the decomposition of lowdensity polyethylene (LDPE) composites was in line with the degradation of natural polymer, accelerating the degradation rate of plastic due to the presence of starch in blend composites [79]. Horvath et al. reported that Kenya, a country in East Africa, took a bold step in banning plastic carrier bags as a result of 100 million plastic bags being supplied by the supermarkets in 2017 [80]. Biodegradable food packaging is one of the best efforts to solve the problems of nonbiodegradable-based counterpart as the latter tend to remain in the environment for hundreds of years [81]. Most authors have reported that the modification of biodegradable polymers displayed improvement in the mechanical, thermal, barrier, and antimicrobial properties while maintaining the stability and extending the shelf life of packaged foods such as fish, cheese, and fruits [82-85]. The utilization of biodegradable polymer seems to be a promising material for food packaging.

This review article emphasizes the properties of biodegradable composite to substitute the utilization of nonbiodegradable composite in terms of biodegradation, mechanical strength, thermal stability, barrier properties, and antioxidant and antimicrobial or antibacterial activity to meet the basic requirements of food packaging.

\section{Nonbiodegradable Composite}

Ho et al. reported that the worldwide production of synthetic polymers has reached 322 million tons per year, in which $20 \%-30 \%$ of municipal solid waste volume in disposal areas were represented by plastics [86]. Most synthetic plastics were designed to be of lightweight, with good mechanical properties, high thermal stability and durability, and high resistance to environmental degradation [87]. A literature survey conducted among Malaysian food hawkers in Kuala Selangor indicated that almost $33 \%$ of respondents used plastic bags to pack their food [88]. Generally, this "white pollution" has generated great concern due to its hydrophobic properties, leading to their long lifetime of hundred years in natural environment [89]. The combination of nanomaterial or other polymers with the film base could improve the barrier performance and mechanical and thermal properties as compared to the use of a single polymer [90]. Therefore, several recently published articles on the modification of nonbiodegradable composite-based food packaging are discussed thoroughly in the following sections.

2.1. Polyethylene (PE). Polyethylene (PE) is the first polyolefin material with an enviable and continuous growth in the food industry since the 1940s [91]. There are two main types of PE (Figure 5), which are low-density polyethylene, LDPE (many short- and long-chain branching), and highdensity polyethylene, HDPE (low amount of branching), in which LDPE exhibits a lower degree of crystallinity than 
TABLE 1: Comparison of degradation rate between nonbiodegradable and biodegradable composites by soil burial method.

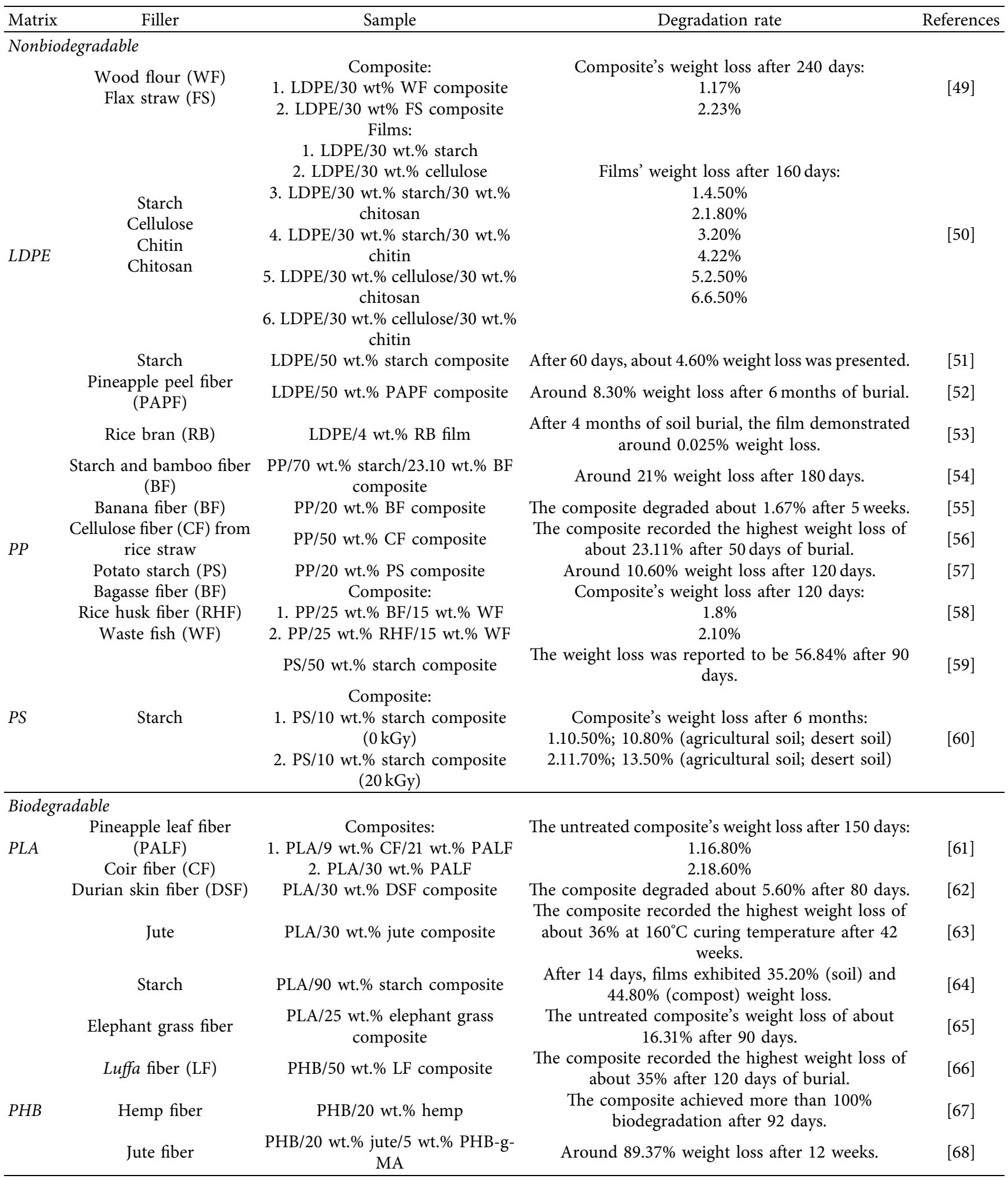


TABLE 1: Continued.

\begin{tabular}{|c|c|c|c|c|}
\hline Matrix & Filler & Sample & Degradation rate & References \\
\hline \multirow{5}{*}{$P C L$} & $\begin{array}{l}\text { Grapefruit seed extract } \\
\text { (GSE) }\end{array}$ & PCL/5 wt.\% GSE & $\begin{array}{l}\text { After } 60 \text { days of burial, the composite film } \\
\text { demonstrated about } 10 \% \text { weight loss. }\end{array}$ & {$[69]$} \\
\hline & Coffee husk $(\mathrm{CH})$ & PCL/5 wt.\% CH composite & $\begin{array}{c}\text { Composite's weight loss of about } 14.80 \% \text { after } 120 \\
\text { days. }\end{array}$ & {$[70]$} \\
\hline & $\begin{array}{l}\text { Organo-nanoclay } \\
\text { Chitosan }\end{array}$ & $\begin{array}{c}\text { Film: } \\
\text { 1. PCL/0.4 wt.\% clay/5 wt.\% } \\
\text { glycerol monooleate } \\
\text { 2. PCL/0.4 wt. } \% \text { clay/10 wt.\% } \\
\text { glycerol monooleate/25 wt. } \% \\
\text { chitosan }\end{array}$ & $\begin{array}{c}\text { Films' weight loss after } 5 \text { months: } \\
1.6 .70 \% \\
2.100 \%\end{array}$ & {$[71]$} \\
\hline & $\begin{array}{l}\text { Clay montmorillonite } \\
(\mathrm{CNa}+) \\
\text { Clay Cloisite 30B (C30B) } \\
\text { Clay Cloisite 20A } \\
\text { (C20A) }\end{array}$ & $\begin{array}{l}\text { Composites: } \\
\text { 1. PCL/5 wt. } \% \mathrm{CNa}+ \\
\text { 2. PCL/5 wt. } \% \mathrm{C} 30 \mathrm{~B} \\
\text { 3. PCL/5 wt. } \% \mathrm{C} 20 \mathrm{~A}\end{array}$ & $\begin{array}{c}\text { Composite's weight loss after } 6 \text { months: } \\
1.41 .50 \% \\
2.15 .30 \% \\
3.51 .90 \%\end{array}$ & {$[72]$} \\
\hline & $\begin{array}{c}\text { Organoclay (Cloisite } \\
\text { 15A) }\end{array}$ & $\begin{array}{l}\text { Composites: } \\
\text { 1. PCL42/5 wt. } \% \text { clay } \\
\text { 2. PCL80/5 wt. } \% \text { clay }\end{array}$ & $\begin{array}{c}\text { Composite's weight loss after } 13 \text { weeks: } \\
1.30 \% \\
2.40 \%\end{array}$ & {$[73]$} \\
\hline \multirow{3}{*}{$P B S$} & $\begin{array}{l}\text { Microcrystalline } \\
\text { cellulose (MCC) }\end{array}$ & PBS/40 wt.\% MCC composite & $\begin{array}{l}\text { The weight loss was reported to be } 100 \% \text { around } 65 \text { to } \\
\qquad 70 \text { days. }\end{array}$ & {$[74]$} \\
\hline & $\begin{array}{l}\text { Sugarcane rind fiber } \\
\text { (SRF) }\end{array}$ & PBS/5 wt.\% SRF composite & About $19.20 \%$ weight loss after 100 days. & {$[75]$} \\
\hline & $\begin{array}{l}\text { Rubberwood powder } \\
\text { (RWP) }\end{array}$ & PBS/40 wt.\% RWP composite & $\begin{array}{l}\text { The weight loss was reported to be } 8.80 \% \text { after } 60 \\
\text { days. }\end{array}$ & {$[76]$} \\
\hline
\end{tabular}

LDPE, low-density polyethylene; PP, polypropylene; PS, polystyrene; PLA, polylactic acid; PHB, polyhydroxybutyrate; PHB-g-MA, polyhydroxybutyrategrafted maleic anhydride; PCL, polycaprolactone; PBS, polybutylene succinate.

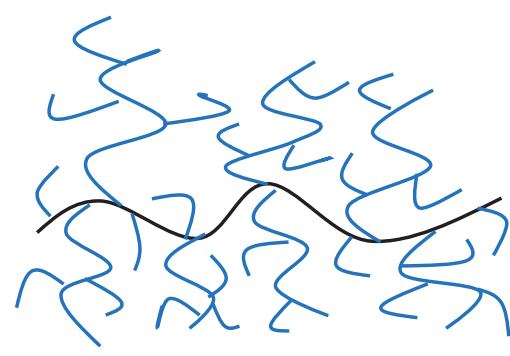

(a)

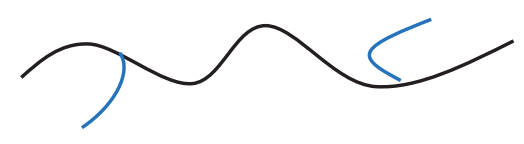

(b)

FIGURE 5: Schematic representation of the structure of (a) LDPE and (b) HDPE.

HDPE [92]. Among the other PEs, LDPE is suitable for food packaging owing to its favorable moisture barrier and high thermal stability along with excellent resistance to abrasion and chemicals [93]. Although the merging of low cost, nontoxicity, superior sealing performance, excellent mechanical strength, and thermal and chemical resistance makes this PE to be widely used, its low barrier properties could limit its use for food packaging application [94, 95]. The chemical structure of PE is shown in Figure 6.

He et al. aimed to evaluate the quality and stability of garlic cloves packed in PET, PE, aluminized kraft paper (AKP), single kraft paper (SKP), and mesh bag (MB) after 180 days of storage at $-2^{\circ} \mathrm{C}$ [95]. It was clearly seen that the PET, $\mathrm{PE}$, and AKP that contained the garlic cloves did not show any germination during storage. Conversely, about $100 \%$ germination rate was achieved for the cloves packed in SKP and $\mathrm{MB}$ after 90 days of storage due to the low ability to prevent water and gas from passing and thus accelerated the germination rate of garlic. Garlic cloves packed with PE recorded the lowest respiratory intensity with $12.25 \%$, while the highest respiratory intensity of garlic cloves stored in AKP by $149.30 \%$ was observed after 120 days of storage in contrast to 0 day of storage $\left(34.85 \mathrm{mg} \bullet \mathrm{kg}^{-1} \mathrm{~h}^{-1}\right)$. After 90 days, there was no significant change in the water content of garlic cloves packed in PE and SKP. Therefore, PE can be regarded as the most effective packaging material, which effectively reduces the deterioration of garlic clove cell membrane.

Eyssa et al. investigated the capability of irradiated HDPE with different nanoparticles: $\mathrm{ZnO}$ or Ag to preserve the stored grains of wheat [96]. The prominent increment in tensile strength (TS) incorporated with higher nanoparticle concentrations and irradiation doses was demonstrated due to the effect of radiation-induced crosslinks. As a result, the TS was boosted up to $177 \%$ and $158 \%$ by incorporating both 2 wt.\% $\mathrm{ZnO}$ and $\mathrm{Ag}$, respectively, with the optimum dose at $75 \mathrm{kGy}$ than the unirradiated HDPE (12.86 MPa). This 


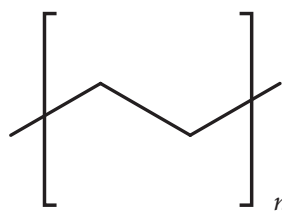

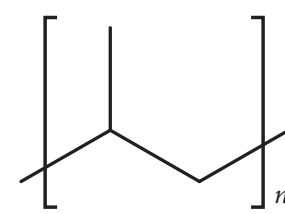

(a)

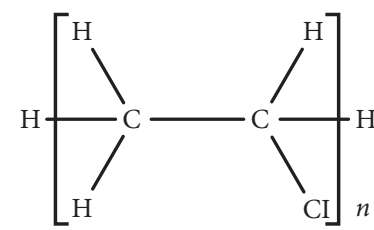

(c)

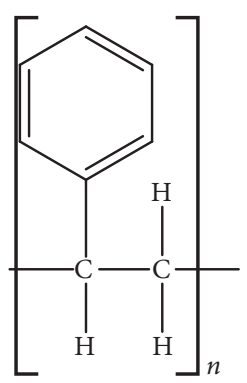

(d)

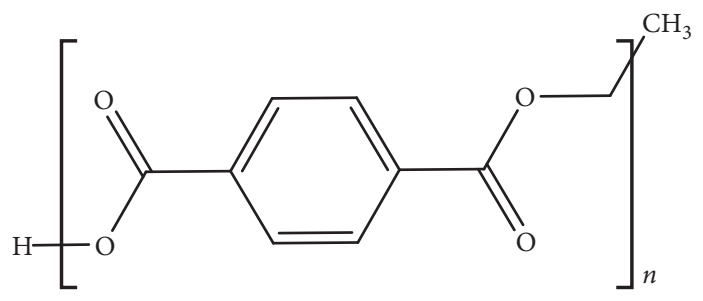

(e)

Figure 6: Chemical structure of (a) polyethylene, (b) polypropylene, (c) polyvinyl chloride, (d) polystyrene, and (e) polyethylene terephthalate as nonbiodegradable composite-based food packaging.

behavior was related to the reaction between zinc ion in $\mathrm{ZnO}$ and lone pair of electron on oxygen atom in vinyl triethoxysilane (VTES) coupling agent, giving a homogenous dispersion of $\mathrm{ZnO}$ into the HDPE film. Notably, inverse data were obtained for both nanocomposites with the reduction in elongation at break (EB) by increasing nanoparticle concentrations and radiation dose $(75 \mathrm{kGy})$. Even though the HDPE film was more thermally stable than that of nanocomposites, the irradiation was helpful in improving its thermal stability. Interestingly, $\mathrm{HDPE} / 2$ wt.\% $\mathrm{Ag}$ nanocomposite film with a dose of $75 \mathrm{kGy}$ presented the best formulation along with $100 \%$ mortality rate toward Sitophilus granaries after five days of storage.

The impact of PE/PP film assisted with alkali-treated wheat straw (WS) was explored by Dixit and Yadav [97]. The response surface methodology (RSM) showed that the optimum variables of $1.80 \mathrm{~g} \mathrm{PE}, 1.20 \mathrm{~g} \mathrm{PP}$, and $1.20 \mathrm{~g}$ treated WS yielded $45.02 \mathrm{MPa}$ TS (tensile strength), $120 \% \mathrm{~EB}$ (elongation at break), and $51.74 \mathrm{~g} \bullet \mathrm{m}^{-2}$ day $^{-1}$ WVTR (water vapor transmission rate). A notable decrease in TS and EB was observed in both composites with values of $26.88 \%$; $5.85 \%$ (native WS) and $3.20 \% ; 2.07 \%$ (treated WS), respectively, than the neat $\mathrm{PE} / \mathrm{PP}$ matrix $(46.50 \mathrm{MPa} \mathrm{TS}$; $122.05 \% \mathrm{~EB})$. The poor interfacial adhesion between polymer and native WS was the reason behind the significant reduction in mechanical property for $\mathrm{PE} / \mathrm{PP} /$ native $\mathrm{WS}$. Apart from that, the WVTR increased for both composites, as evident by $178.11 \%$ (native WS) and $9.24 \%$ (treated WS) with respect to the PE/PP matrix $\left(47.50 \mathrm{~g} \bullet \mathrm{m}^{-2} \mathrm{day}^{-1}\right)$. The surface roughness and good compatibility of treated composite film represented much better barrier properties. However, both polymeric composite films still maintained their hydrophobic properties. This suggested that the inclusion of treated biomass in polymer matrix could widen its usage for green packaging.
The fabrication of active packaging, which is composed of LPDE-based film and polyisoprene natural rubber, was evaluated by Gaikward et al. [98]. Throughout the study, 20 wt.\% polyisoprene possessed optimum mechanical strength with $12.72 \%$ (TS) and $10.62 \%$ (EB), whereas 5 wt.\% polyisoprene showed much better barrier properties with the lowest increment values for oxygen transmission rate, OTR (41.59\%), and water vapor permeability, WVP (10.34\%), with respect to the neat LDPE $(6.13 \mathrm{MPa} ; 121.39 \% \mathrm{~EB}$;

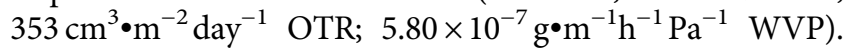
This might refer to the interaction between LDPE and polyisoprene leading to higher strength, while the hydrophilic characteristic of polyisoprene was the reason for higher WVP. For thermal stability, the addition of polyisoprene does not significantly influence the thermal degradation of LDPE composite film. Overall, about $14 \%$ bacterial reduction seems to be related to the absence of oxygen for beef jerky packed with LDPE/20 wt.\% polyisoprene film after 90 days of storage as compared to the LDPE film.

2.2. Polypropylene $(P P)$. There is an ever-growing interest in the development of polypropylene-based packaging as it can be utilized in food contact applications, especially for microwavable food container [99]. PP (Figure 6) has a linear hydrocarbon chain, which only consists of carbon atoms in its structure with hydrophobic properties [8]. Scanning the literature review, PP undeniably has been one of the outstanding polymers due to its low cost, low water vapor transportation, gas permeability, excellent resistance to chemicals, and abrasion along with high-temperature durability [100]. Despite their remarkable characteristics, the difficulty in degradation and poor oxygen barrier of PP restrict this material from being widely used in the food industry [101]. 
The performance of PP composites, which comprised of organically modified montmorillonite (OMMT) with iron nanoparticles, was reported by Khalaj et al. [101]. The introduction of 2 wt.\% OMMT boosted the mobility distance of the gas molecules, leading to a reduction in OTR and WVTR by $22.22 \%$ and $33.33 \%$, respectively, in contrast to the neat PP $\left(1.80 \mathrm{~cm}^{3} \bullet \mathrm{m}^{-2}\right.$ day $^{-1}$ OTR; $0.60 \mathrm{~g} \bullet \mathrm{m}^{-2}$ day $^{-1}$ WVTR). Meanwhile, the insertion of $0.2 \mathrm{wt} \%$ nanoparticles resulted in the decrement in permeability of neat PP by both $55.56 \%$ (OTR) and $76.67 \%$ (WVTR). This might be due to the nanoparticles, which increased the intercepting and scavenging of oxygen through a chemical reaction. Moreover, a slight improvement in thermal stability (melting temperature, $T_{m}$ ) of about $0.98 \%$ was also noted with 2 wt. $\%$ OMMT/0.2 wt.\% nanoparticles as compared to PP/1 wt.\% OMMT $\left(T_{m}: 163.90^{\circ} \mathrm{C}\right)$. For mechanical strength, the highest increment was recorded at 2 wt.\% OMMT/0.05 wt.\% nanoparticles with $\sim 17.86 \%$ (TS) and $\sim 81.82 \%$ (modulus) as compared to the neat PP (28 MPa TS; $495 \mathrm{MPa}$ modulus). Overall, the incorporation of 0.05 wt.\% iron nanoparticles and 2 wt.\% OMMT into neat PP was recommended because the resulting composite exhibited superior barrier and mechanical properties.

Returnable seafood packaging that contained antimicrobial additive in PP-based film was discussed by Singh et al. to reduce the waste and carbon footprint [102]. In contrast to the PP film (40.80 MPa TS; $5.05 \% \mathrm{~EB})$, reduction of $13.94 \%$ TS with a slight increment of $0.67 \%$ elongation was noted in the case of PP/3 wt.\% silver-zinc (AgZn) composite film, owing to the plasticization effect of additive in the matrix. The improvement in thermal stability was also associated with the presence of active material in the composite film. Further, the additive had reduced up to $99 \%$ bacteria for both Staphylococcus aureus (S. aureus) and Escherichia coli (E. coli) after $24 \mathrm{~h}$ with an optimum concentration of 10 wt.\%. Meanwhile, about $50 \%$ of antimicrobial properties was observed after the fifth wash cycle, presenting superior action against Gram-negative microorganisms. The study declared that the silver ions played a key factor in the formation of reactive oxygen molecules and thus inhibited the bacterial respiration and subsequently reduced the deterioration and food-borne disease toward purchasers.

Prabhu and Devaraju described the influence of silver zinc, which contained zeolite coating on biaxial-oriented polypropylene (BOPP/SZZ) films for meat packaging [103]. From this investigation, the BOPP/SZZ packaging film demonstrated significantly better barrier properties with regard to the OTR and WVTR with $16.17 \%$ and $69.03 \%$, respectively, in contrast to BOPP film $\left(4.76 \mathrm{~cm}^{3} \cdot \mathrm{m}^{-2}\right.$ day $^{-1}$ OTR; $\left.22.60 \mathrm{mg} \bullet \mathrm{dm}^{-2} \mathrm{WVTR}\right)$. The increase in coated SZZBOPP might be due to the silver ion, which improved the molecular bonding of aluminium on the film. Additionally, the antimicrobial activity was also successfully reduced up to $92.67 \%$ after $4 \mathrm{~h}$ and highly reduced to $98.50 \%$ for the next $24 \mathrm{~h}$ by inhibiting the following microbes: Listeria monocytogenes (L. monocytogenes), Clostridium perfringens (C. perfringens), Salmonella enteritidis (S. enteritidis), E. coli, and Campylobacter and thus proved the efficacy of SZZ as an antimicrobial agent in BOPP film. All in all, improved properties of the packaging film helped to extend the shelf life of meat for 10 days in a refrigerated storage.

The combination of sodium chloride $(\mathrm{NaCl})$ treatment with PP packaging was figured out by Zhang et al. [104]. According to the study, freshly cut ginger dipped in $0.05 \mathrm{~mol} \cdot \mathrm{L}^{-1} \mathrm{NaCl}$ solution and packed with $\mathrm{PP}$ resulted in a minimum weight loss of $\sim 0.70 \%$ with retained firmness of up to $\sim 21.54 \%$ as compared to pure water combined with PP packaging ( $0.83 \%$ weight loss: $13 \mathrm{~N}$ firmness) after 20 days of storage. The inhibition of surface browning due to the $\mathrm{NaCl}$ treatment was proposed to be the reason for this behavior. It was found that in the case of the $\mathrm{O}_{2}$ level the values of $\sim 3 \%$ (water $+\mathrm{PP}$ ) and $\sim 2 \%$ (aq. $\mathrm{NaCl}+\mathrm{PP}$ ) were presented, but in the case of $\mathrm{CO}_{2}$ level, the values of $\sim 7 \%$ (water $+\mathrm{PP}$ ) and $\sim 8.30 \%$ (aq. $\mathrm{NaCl}+\mathrm{PP}$ ) were described. After 20 days, the antibacterial and antifungal reduction during the storage of fresh ginger was reported to be at $41.30 \%$ and $31.39 \%$, respectively, in contrast to the water + PP packaging (4.14 log $\left.\mathrm{CFU} \cdot \mathrm{g}^{-1} ; 4.11 \log \mathrm{CFU} \bullet \mathrm{g}^{-1}\right)$. Overall, the ginger treated with $\mathrm{NaCl}$ combined with PP packaging had the best appearance quality.

\subsection{Polyvinyl Chloride (PVC). The utilization of around 39.3} million metric tons in 2013 ranked polyvinyl chloride (PVC) (Figure 6) as the third most applied thermoplastic-based food packaging after PE and PP [105,106]. Meanwhile, consumer demands with regard to low cost, lightweight, superior chemical resistance, and barrier toward burning, as well as great desire for fresh products, are also driving this escalation [107]. The major disadvantages of PVC as food packaging are high stiffness with poor flexibility, low thermal properties, and difficulties in melt processing. In fact, the high chlorine content and stability of PVC have influenced the disposal and treatment of PVC waste as the incineration process could contribute to the emission of hydrogen chloride and organic halogen compounds [108,109].

In recent years, Braga et al. synthesized an active antimicrobial film of PVC, which contained silver (Ag) nanoparticles as an excellent alternative to modified atmosphere packaging (MAP) [110]. The incorporation of $8 \mathrm{wt} . \%$ Ag into PVC film recorded an optimum thermal stability over other loadings. Surprisingly, the nanocomposite film of PVC/1 wt.\% Ag and PVC/2 wt.\% Ag demonstrated good antimicrobial activity against Fusarium solani (F. solani) and Bacillus subtilis (B. subtilis), respectively, as compared to the no inhibitory action of $4 \mathrm{wt} . \%$ and $8 \mathrm{wt} . \% \mathrm{Ag}$ and neat films. The lack of antimicrobial action was believed to be because of poor diffusion through the PVC matrix, which subsequently slowed the migration of Ag through the culture medium. The study also found that PVC/1 wt.\% Ag was the best nanocomposite film in expanding the shelf life of bread for 15 days of storage than the PVC film (five days of storage).

Yadav et al. focused on the aptitude of graphene oxide dispersion in polyvinyl chloride/waterborne castor alkyd (PVC/WCA/GO) nanocomposite film [108]. The insertion of 0.5 wt.\% GO into PVC/WCA film statistically enhanced 
the TS and modulus of nanocomposite blend with values of $259.97 \%$ and $185.48 \%$ in contrast to PVC film (6.22 MPa TS; 255.94 MPa modulus), as well as about $26.14 \%$ and $141.07 \%$ relative to PVC/WCA film $(17.75 \mathrm{MPa}$ TS; $303.09 \mathrm{MPa}$ modulus), respectively. The GO was declared to be responsible for improving the mechanical strength of nanocomposite film as a consequence of homogenous distribution, polar-polar interaction, and hydrogen bonding formation of the GO with PVC/WCA matrix. The PVC/ WCA/0.5 wt.\% GO nanocomposite was more thermally stable than PVC/WCA film $\left(T_{d}: 315^{\circ} \mathrm{C}\right)$, as evident by the increment of about $26.98 \%$, relating to the strong hydrogen bonds and van der Waals forces that occurred among WCA, GO sheets, and PVC molecules. This indicated that the prepared nanocomposite films were beneficial material for food packaging at an industrial scale.

The comparison between meat-packed conditions and atmosphere of normal air (PVC wrap) and MAP were evaluated by Chmiel et al. [111]. Based on MAP, the lower $\mathrm{O}_{2}$ and higher $\mathrm{CO}_{2}$ levels were recorded by $68.80 \%$ and $24.90 \%$ than the initial levels with $75.70 \%$ and $20.20 \%$ (display case), respectively, after nine days of storage. The consumption of gas by bacteria, meat-specific enzymes, and gases exchange would be the cause of $\mathrm{O}_{2}$ level reduction, whereas the use of oxygen for bacterial respiration led to the higher $\mathrm{CO}_{2}$ concentration as their products. Moreover, meat in PVC wrap and in MAP stored in a cooling room could extend the shelf life until eight and more than nine days, respectively. This can be seen from the growth of Pseudomonas spp. around 64.80\% (PVC foil) and 52.42\% (MAP) after eight days. For the display case, the unacceptable quality was observed on day 7 for PVC wrap, while the acceptable quality was presented by MAP after nine days of storage. In short, MAP had the tendency to expand the meat shelf life by at least one and two days in the cooling room and the display case storage, respectively.

The preparation of duo-functional PVC films with additive mixture (MA) as pure and encapsulated potassium metabisulfite for minimally processed apples was analyzed by Foralosso et al. [112]. In terms of thermal stability, no thermal degradation difference was observed between the control film and the films incorporated with additives when the concentration of MA was increased. The insertion of 0.1 wt.\% MA resulted in the lowest decrease in EB (machine direction) of about $32 \%$ than the neat PVC (187.60\%). Meanwhile, 2 wt.\% MA presented the best film among others, in which the bacterial reduction was achieved up to $\sim 25 \%, \sim 29.09 \%$, and $21.82 \%$ at $4^{\circ} \mathrm{C}, 8^{\circ} \mathrm{C}$, and $20^{\circ} \mathrm{C}$, respectively, after 20 days as compared to the control film $(4.80$ $\log \mathrm{CFU} \bullet \mathrm{g}^{-1} ; 5.50 \log \mathrm{CFU} \bullet \mathrm{g}^{-1} ; 5.50 \log \mathrm{CFU} \cdot \mathrm{g}^{-1}$ at $4^{\circ} \mathrm{C}, 8^{\circ} \mathrm{C}$, and $20^{\circ} \mathrm{C}$ ). These reductions might be due to the generation of antimicrobial effect via KM dissociation at the beginning of storage. Meanwhile, EKM within silica matrix may require a longer time to generate $\mathrm{SO}_{2}$ antimicrobial, keeping the reducing effect for a longer period. Notably, the duofunctional PVC/2 wt.\% MA film has higher ability to extend the life span of cut apples up to eight days of storage at $8^{\circ} \mathrm{C}$ as compared to the PVC film (four days).
2.4. Polystyrene (PS). Polystyrene-based food packaging occupies fourth place in the food industry, which is after PE, PVC, and PP [113]. PS (Figure 6) is an aromatic polymer that is formed through the polymerization process of styrene monomers [114]. Its unique characteristics, such as excellent mechanical properties, high thermal stability, low moisture penetration, ease of processing, and low cost, make PS as a high potential material for food packaging [115]. However, the nondegradability behavior and high recycling cost of PS are the primary problems since it is highly stable and has a high molecular weight. Besides, the toxicity and recalcitrant compounds of PS also lead to environmental pollution, human health problems, and disruption of ecosystems $[86,116]$.

Ibrahim et al. explored the efficiency of zinc oxide nanoparticles (5 wt.\% $\mathrm{ZnO}$ ) incorporated in PS-based food packaging [117]. The thermal analysis demonstrated that the degradation temperature $\left(T_{d}\right)$ of nanocomposites had increased by about $35.81 \%$ as compared to the neat PS ( $T_{d}$ : $296^{\circ} \mathrm{C}$ ). This means that the presence of $\mathrm{ZnO}$ was responsible for delaying the decomposition rate of nanocomposites. It was worth to note that the prepared nanocomposites revealed a much better antimicrobial impact toward Staphylococcus aureus (S. aureus), Pseudomonas aeruginosa ( $P$. aeruginosa), Candida albicans (C. albicans), and Aspergillus niger (A. niger) relative to non-inhibition properties of neat PS. In a similar study, Fakhri et al. mentioned that the combination of less than 1.5 wt.\% $\mathrm{ZnO}$ with $3.5 \mathrm{wt} . \%$ nanoclay $(\mathrm{C} 15 \mathrm{~A})$ in neat PS presented the optimum TS [115]. Meanwhile, the range of $0.65 \mathrm{wt} . \%{ }^{<} \mathrm{ZnO}^{<} 1.5 \mathrm{wt} . \%$ and C15A $>3.5$ wt.\% resulted in maximum modulus. These could be explained by the higher interfacial adhesion between both nanoparticles, contributing to the homogenous distribution inside the matrix. Overall, the composition of nanoparticles played a key role in the fabrication of nanocomposites as they tend to agglomerate and thus cause the reduction in mechanical strength.

Eksirinimitr et al. evaluated the efficiency of PS doped with two different forms (solid and liquid) of antimicrobial agent, namely 2-hydroxypropyl-3-piperazinyl-quinoline carboxylic acid methacrylate (HPQM) [118]. The achievements of $99.90 \%$ bacterial reduction against E. coli for PS/ HPQM-neu and PS/HPQM-water (more suitable) specimens after $4 \mathrm{~h}$ with the ideal dosage of $1250 \mathrm{ppm}$ HPQM were noted. The interaction between the phenyl group and the silanol group ( $\mathrm{Si}-\mathrm{OH})$ of Neusilin played a main factor in the reduction in bacteria. The minimal antibacterial usage did not alter the mechanical strength of PS doped composites. It was found that the significant reduction in antibacterial performance at different rates was revealed by all specimens for the immersion in water $\left(80^{\circ} \mathrm{C}\right)$, detergent solution (room temperature and $80^{\circ} \mathrm{C}$ ), and accelerated UV aging. It is recommended that the PS-based food container material is suitable for application at room temperature as thermal and UV aging factors could lead to polymer degradation.

Hegazy et al. studied the performance of low-density polyethylene/polystyrene/maleic anhydride/magnesium hydroxide (70 wt.\% LDPE/30 wt.\% PS/10 wt.\% MA/5 wt.\% $\mathrm{Mg}(\mathrm{OH})_{2}$ ) blend nanocomposite toward gamma irradiation [119]. The higher irradiation dose increased the TS of LDPE 
film and nanocomposite film, but a prominent decrease was observed at $40 \mathrm{kGy}$ for LDPE. About $8.89 \%$ increment in TS was exhibited for irradiated nanocomposite due to the effect of crosslinking, with $~ 55 \%$ decrement in EB as compared to the irradiated LDPE (9 MPa TS; 65\% EB) at $30 \mathrm{kGy}$. Moreover, the incorporated $\mathrm{Mg}(\mathrm{OH})_{2}$ nanoparticles as additive did not influence the mechanical properties of nanocomposite. As compared to the neat $\operatorname{LDPE}\left(T_{d}\right.$ : $397.30^{\circ} \mathrm{C}$ at $25 \mathrm{kGy} ; 386.20^{\circ} \mathrm{C}$ at $0 \mathrm{kGy}$ ), the optimum thermal stability of nanocomposite increased by around $9.21 \%$ at $25 \mathrm{kGy}$ as compared to $3.26 \%$ at $0 \mathrm{kGy}$. In conclusion, the irradiation method was beneficial to enhance the properties of prepared nanocomposite, especially in the food packaging sectors.

2.5. Polyethylene Terephthalate (PET). Polyethylene terephthalate (PET), which belongs to the class of aromatic polyester, is the most well-known material used for beverage container [120]. The condensation polymerization of PET (Figure 6) involves the esterification reaction of monoethylene glycol and terephthalic acid or dimethyl terephthalate [121]. As compared to the other types, PET possesses superior mechanical strength, gas retention properties, thermal and chemical stability, and cheap material [122]. Even though PET can be recycled, the presence of aromatic moieties makes PVC impervious toward hydrolytic degradation and microbial attack [122].

Ding et al. monitored the performance of black garlic using different types of packaging materials: polyethylene terephthalate bottles (PETBs), kraft paper bags (KPBs), and aluminium-laminated polyethylene bags (ALPBs) at $4^{\circ} \mathrm{C}$ and $20^{\circ} \mathrm{C}$ after 90 days of storage [123]. According to data, the moisture content values of garlic stored in each packaging were reported to be in the order of ALPB (30.07\%)> PETB $(25.66 \%)>\mathrm{KPB}(24.05 \%)$ at $4^{\circ} \mathrm{C}$. Meanwhile, the order of PETB $(25.17 \%)>$ ALPB $(25.10 \%)>$ KPB $(22.73 \%)$ was noted at $20^{\circ} \mathrm{C}$. In terms of thermal stability, PETB presented the second highest with the stability of $3.03 \%\left(4^{\circ} \mathrm{C}\right)$ and lowest stability of about $3.74 \%\left(20^{\circ} \mathrm{C}\right)$ among others, as compared to the unpacked black garlic $\left(T_{m}: 56.1^{\circ} \mathrm{C}\right)$. In similar types of study, Giuffre et al. clarified that the highest moisture content was presented by PET-packed raspberries $(90.58 \%)$, whereas fruits without any film exhibited the lowest moisture content $(87.73 \%)$ after nine months of storage in the freezer [124].

Antonis evaluated the storage conditions of PET bottles incorporated in olive oil for 12 months of storage [125]. Their findings indicated that the prominent differences in OTR at $15^{\circ} \mathrm{C}$ were statistically significant for the total storage period as compared to bottles that contained oil kept at $30^{\circ} \mathrm{C}$ and $40^{\circ} \mathrm{C}$. About $25 \%$ increment was revealed by the oil-containing bottles at $15^{\circ} \mathrm{C}$ during illuminated environment relative to the unfilled PET bottle $\left(8.00 \mathrm{~cm}^{3} \cdot \mathrm{m}^{-2} \mathrm{day}^{-1}\right)$ after 12 months. The presence of humidity and oil penetration had increased the OTR. Meanwhile, the binding of water at polar sites of PET polymer could hinder the flow of oxygen to pass through, which resulted in a lower OTR for unfilled PET bottle. The thermal analysis indicated that significant changes in thermal properties were obtained within the first four months, among the filled PET and control bottle. In other types of PET modification, Essabti et al. achieved an OTR reduction of up to $94.87 \%$ with two coated layers of $1 \mathrm{wt} . \%$ chitosan:40 wt.\% vermiculite nanoclay on $130 \mu \mathrm{m}$ PET film $\left(0.31 \mathrm{~cm}^{3} \cdot \mathrm{m}^{-2} \mathrm{day}^{-1}\right)$ [126]. Therefore, these improved barrier behaviors support its usage in food packaging application.

Ishtiaque et al. assessed the gas permeation on PET film coated with natural polyphenolic-gelatin mixture (PGM) [127]. It was worth to note that the OTR and WVTR of PETPGM film decreased by $22.56 \%$ and $23.08 \%$, respectively, with regard to the PET film $\left(82 \mathrm{~cm}^{3} \cdot \mathrm{m}^{-2} \mathrm{day}^{-1}\right.$ OTR; $\left.1.30 \mathrm{~g} \bullet \mathrm{m}^{-2} \mathrm{day}^{-1} \mathrm{WVTR}\right)$. This was reasonable because the coated PET film polymer structure became more powerful and resistant toward oxygen strong protective coating, owing to the reduction spaces in the coating with regard to the uncoated PET. Noh et al. also investigated similar characteristics with the incorporation of nanoparticles in PET-based food packaging film [128]. The introduction of 2 wt.\% graphene nanoplatelets (GNPs) demonstrated up to 99\% reduction in OTR with the highest strength of $\sim 23.93 \%$ TS and $\sim 191.15 \%$ modulus as compared to the neat PET (28 MPa TS; $190 \mathrm{MPa}$ modulus; $12.30 \mathrm{~cm}^{3} \bullet \mathrm{m}^{-2} \mathrm{day}^{-1}$ ).

Nayak and Khuntia evaluated the efficiency of PET-based film in conjunction with treated Moringa oleifera fruit fibers [129]. Based on the fiber loadings, 20 wt.\% fiber reinforcement had the optimum set of mechanical properties, which increased by $5.16 \% ; 21.01 \%$; and $4.60 \%$ (untreated) and $19.29 \%$; $47.08 \%$; and $13.70 \%$ (treated) for TS, modulus, and $\mathrm{EB}$, respectively, in contrast to the neat PET (55.26 MPa TS; $2570 \mathrm{MPa}$ modulus; $19.10 \% \mathrm{~EB})$. The improved mechanical strength was undoubtedly related to the good adhesion between hydrophilic fiber and hydrophobic matrix. The need of chemical treatment of fiber should be considered as the presence of lignin could deteriorate the strength of prepared composites. From the viewpoint of thermal stability, the composite $\left(T_{d}: 540^{\circ} \mathrm{C}\right)$ exhibited excellent stability than the neat PET $\left(T_{d}: 480^{\circ} \mathrm{C}\right)$. This suggested that the utilization of fiber could convert the waste to wealth as it exhibited higher mechanical and thermal properties of final composite.

To sum up, the single-use nonbiodegradable composite exhibited excellent properties and performance as compared to the single-use biodegradable composite. The constantly growing production of commercial food packaging has gained considerable attention due to their attractive properties. The degradation of nonbiodegradable-based composites is a great challenge as the composite is increasingly used and the demand is high. Efforts were made to overcome these problems through reuse and recycling, but most of the plastics are nonrecyclable. Consequently, the uncontrolled growth of nonbiodegradable plastic wastes has led to critical environmental pollution. Table 2 presents the additional uses of nonbiodegradable composites for food packaging application. 
TABLE 2: Nonbiodegradable composite-based food packaging.

\begin{tabular}{|c|c|c|c|c|c|}
\hline $\begin{array}{l}\text { Control } \\
\text { sample }\end{array}$ & Properties & Modified sample & Properties & Food products & References \\
\hline LDPE Film & 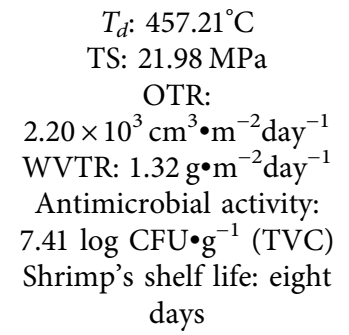 & $\begin{array}{c}\text { LDPE/rosemary essential } \\
\text { oil + cinnamon essential oil }(1: 1 \\
\text { wt. } \%) \text { film }\end{array}$ & $\begin{array}{c}T_{d}: 450.53^{\circ} \mathrm{C} \\
\text { TS: } 18.59 \mathrm{MPa} \\
\text { OTR: } \\
1.31 \times 10^{3} \mathrm{~cm}^{3} \bullet \mathrm{m}^{-2} \text { day }^{-1} \\
\text { WVTR: } 0.72 \mathrm{~g} \bullet \mathrm{m}^{-2} \text { day }^{-1} \\
\text { Antimicrobial activity: } \\
\text { 6.03 log CFU } \bullet \mathrm{g}^{-1} \text { (TVC) } \\
\text { Shrimp's shelf life: } 12 \text { days }\end{array}$ & $\begin{array}{l}\text { Pacific white } \\
\text { shrimps }\end{array}$ & {$[93]$} \\
\hline PP Film & $\begin{array}{c}\text { TS: } \sim 48 \mathrm{MPa} \\
\text { EB: } \sim 600 \% \\
\text { WVP: } \\
1.57 \times 10^{-7} \mathrm{~g} \bullet \mathrm{m}^{-1} \mathrm{~h}^{-1} \mathrm{~Pa}^{-1} \\
\text { Bacterial count: } \\
\sim 8.70 \log \mathrm{CFU} \bullet \mathrm{g}^{-1} \\
\quad(\text { E. coli) } \\
\sim 8.62 \log \text { CFU } \bullet \mathrm{g}^{-1} \\
\text { (S. aureus) }\end{array}$ & $\begin{array}{l}\mathrm{PP} / 2 \text { wt.\% sorbic acid composite } \\
\text { film }\end{array}$ & 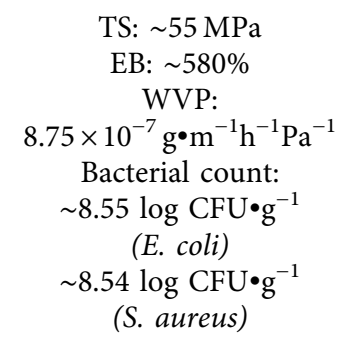 & $\begin{array}{l}\text { Bakery and dairy } \\
\text { products, fresh } \\
\text { product, and } \\
\text { poultry products }\end{array}$ & {$[130]$} \\
\hline & $\begin{array}{l}\text { TS: } 3.56 \mathrm{MPa} \\
\text { EB: } 163.62 \%\end{array}$ & & $\begin{array}{l}\text { TS: } 3.37 \mathrm{MPa} \\
\text { EB: } 116.56 \%\end{array}$ & & \\
\hline PVC Film & $\begin{array}{c}\text { Bacterial count: } \\
\sim 6.50 \text { log CFU } \bullet g^{-1} \text { (TVC) } \\
\text { Chicken's shelf life: five } \\
\text { days }\end{array}$ & $\begin{array}{c}\text { PVC/0.5 wt.\% Ag nanocomposite } \\
\text { film }\end{array}$ & $\begin{array}{c}\text { Bacterial count: } \\
\sim 5.80 \text { log CFU } \bullet g^{-1}(\mathrm{TVC}) \\
\text { Chicken's shelf life: six } \\
\text { days }\end{array}$ & $\begin{array}{l}\text { Chicken breast } \\
\text { fillets }\end{array}$ & [107] \\
\hline PS Film & $\begin{array}{c}\text { TS: } \sim 22.95 \mathrm{MPa} \\
\text { EB: } \sim 9.50 \% \\
\text { Swelling: } \sim 0.30 \% \\
\text { WVTR: } \\
\sim 7.67 \mathrm{~g} \bullet \mathrm{m}^{-2} \text { day }^{-1}\end{array}$ & $\begin{array}{c}\text { PS/10 wt.\% treated kenaf fiber } \\
\text { composite }\end{array}$ & $\begin{array}{c}\text { TS: } \sim 21.80 \mathrm{MPa} \\
\text { EB: } \sim 212 \% \\
\text { Swelling: } \sim 0.70 \% \\
\text { WVTR: } \\
\sim 12.64 \mathrm{~g} \bullet \mathrm{m}^{-2} \mathrm{day}^{-1}\end{array}$ & NR & {$[131]$} \\
\hline $\begin{array}{l}\text { Corona- } \\
\text { treated } \\
\text { PET film }\end{array}$ & $\begin{array}{l}\text { Chicken's weight loss: } 3 \% \\
\text { Antioxidant activity: none } \\
\text { Bacterial count: } \\
\sim 7.50 \log \text { CFU } \bullet g^{-1} \\
\text { (aerobic) }\end{array}$ & $\begin{array}{l}\text { PET/chitosan + alginate + black } \\
\text { cumin oil }(1: 1: 1 \mathrm{w} / \mathrm{v} . \%) \text { film }\end{array}$ & $\begin{array}{c}\text { Chicken's weight loss: } \\
2.30 \% \\
\text { Antioxidant activity: } \\
21.36 \% \text { (5 layers) } \\
24.31 \% \text { (10 layers) } \\
26.79 \% \text { (15 layers) } \\
\text { Bacterial count: } \\
\sim 7.20 \text { log CFU } \bullet{ }^{-1} \\
\text { (aerobic) }\end{array}$ & $\begin{array}{l}\text { Chicken breast } \\
\text { meat }\end{array}$ & {$[132]$} \\
\hline
\end{tabular}

LDPE, low-density polyethylene; PP, polypropylene; PVC, polyvinyl chloride; PS, polystyrene; PET, polyethylene terephthalate; Td, degradation temperature; WVP, water vapor permeability; WVTR, water vapor transmission rate; OTR, oxygen transmission rate; TS, tensile strength; EB, elongation at break; TVC, total viable count; S. aureus, Staphylococcus aureus; E. coli, Escherichia coli; NR, not reported.

\section{Biodegradable Composite}

European Bioplastics Association has predicted that the worldwide production of biodegradable materials could escalate up to 1086000 tons by 2022 as compared to the production in 2017 with 880000 tons, a growth of $24 \%$ within five years [133]. Biodegradable materials have a tendency to degrade completely by the action of microorganisms through the secretion of enzyme in natural environment. The degradation can also occur through mechanical, thermal, chemical, radiation, or biological processes [134]. Kumar et al. declared that the utilization of modified biodegradable-based composite film has a higher potential to be applied in food packaging owing to its excellent mechanical strength [135]. Even though biodegradable materials could preserve fossil resources and reduce environmental pollution, the higher price and poor barrier performance are the major limitation faced by biodegradable materials at an industrial scale [136]. Therefore, some modifications on biodegradable composite-based food packaging are clearly described in the next section.

3.1. Cellulose. Cellulose (Figure 7) is a polysaccharide chain, which consists of D-glucopyranose units connected by $\beta-1,4$ glycoside linkages, with highly packed structure due to the inter- and intramolecular hydrogen bonds [137, 138]. Among biodegradable materials, cellulose is one of the world's most abundant renewable matter and an attractive natural polymer in the fabrication of green food packaging. Cellulose offers several advantages, including low cost, environmentally friendly, high mechanical strength, nontoxic, 


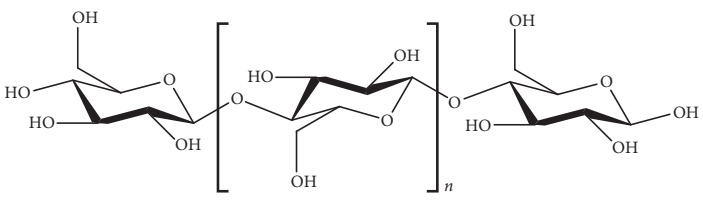

(a)

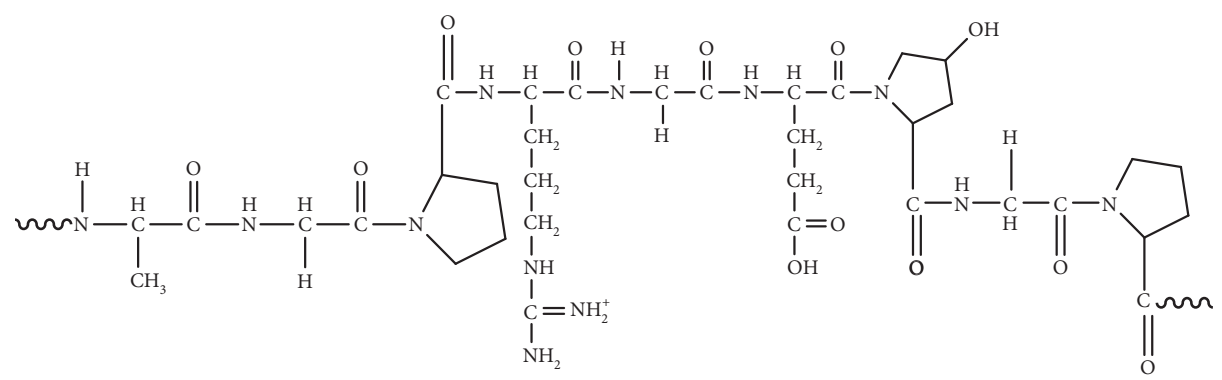

(b)<smiles>CC(O)C(=O)OC(C)C(=O)OC(C)C(=O)O</smiles>

(c)<smiles>CCO[C@@H](C)CC(=O)O</smiles>

(d)<smiles>CC(C)(C)OCCCCCC(=O)C1CCC1</smiles>

(e)<smiles>CC(C)OCCCCOC(=O)CCC(C)(C)C</smiles>

(f)

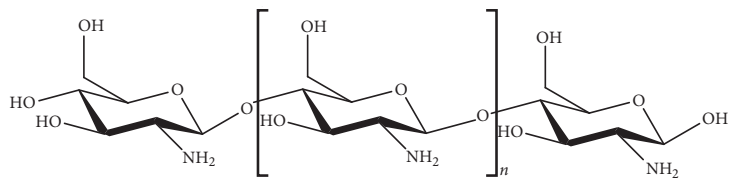

(g)

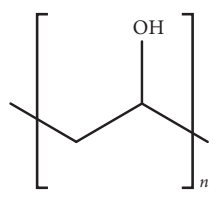

(h)

Figure 7: Continued. 


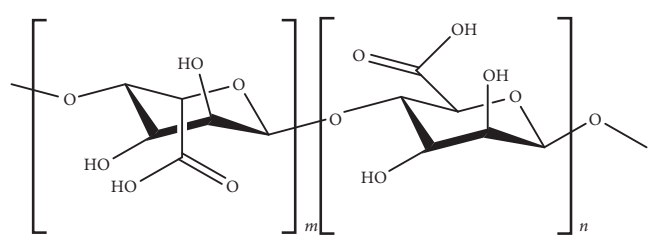

(i)

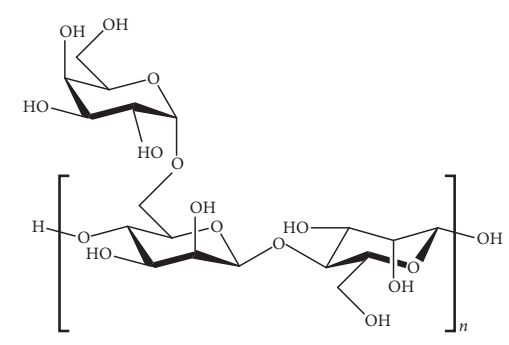

(j)

Figure 7: Chemical structure of (a) cellulose, (b) gelatin, (c) polylactic acid, (d) polyhydroxybutyrate, (e) polycaprolactone, (f) polybutylene succinate, (g) chitosan, (h) polyvinyl alcohol, (i) alginate, and (j) gum arabic as biodegradable composite-based food packaging.

and the abundant functional groups in the structure, and has led to numerous interesting modifications [139, 140]. Although cellulose has a great potential as food packaging material, its high polarity results in much lower barrier properties [141].

The comparison between nanocellulose (NC) film and recycled nanocellulose (RNC) film through the spray coating method was carried out by Shanmugam et al. [136]. In contrast to the virgin film $\left(0.003 \mu \mathrm{m} \bullet \mathrm{s}^{-1} \mathrm{~Pa}^{-1}\right)$, the increment of $\sim 50 \%$ of air permeability for RNC film was still accounted as a better air resistance for packaging application. Unlike air permeability, the WVP for RNF film increased up to $97.77 \%$ relative to the virgin film $\left(1.79 \times 10^{-7} \mathrm{~g}^{\bullet} \mathrm{m}^{-1} \mathrm{~h}^{-1} \mathrm{~Pa}^{-1}\right)$. The low barrier properties of RNC film were related to the agglomeration during recycle process, and the utilization of homogenizer was suggested to completely break the formation of agglomerates within a cellulose nanofiber suspension. Interestingly, the RNC film had a tendency to maintain $\sim 70 \%$ of the strength of the NC film. In conclusion, this recyclable material was seen to be comparable with those of commercial packaging materials, such as PE, PVC, and PS.

Achaby et al. evaluated the performance of polyvinyl alcohol (PVA)/carboxymethyl cellulose (CMC) blend film with cellulose nanocrystals (CNCs) derived from sugarcane bagasse fibers [142]. It was found that the strength of bionanocomposite with 5 wt.\% CNC obtained an optimum increment of $82.96 \%$ and $141.23 \%$ for TS and modulus, respectively, than the $\mathrm{PVA} / \mathrm{CMC}$ film $(64.85 \mathrm{MPa} \mathrm{TS}$; 1138.70 $\mathrm{MPa}$ modulus). These indicated that the high aspect ratio of $\mathrm{CNC}$ and the interaction between matrix and $\mathrm{CNC}$ played a key role in the formation of hydrogen bonds, thereby improving the strength of bionanocomposites. However, the exceeded reinforcement of $10 \mathrm{wt}$ \% CNC was not recommended as it tends to agglomerate in the matrix. Meanwhile, the added 5 wt.\% CNC also showed a slight increase by $2.78 \%$ for thermal stability, while the WVP was reduced by $81.90 \%$ in contrast to the PVA/CMC blend film
$\left(T_{d}: 288^{\circ} \mathrm{C} ; 1.16 \times 10^{-7} \mathrm{~g} \bullet \mathrm{m}^{-1} \mathrm{~h}^{-1} \mathrm{~Pa}^{-1}\right)$. The higher barrier properties might be the cause of homogenous dispersion of $\mathrm{CNC}$ within the matrix and subsequently reduced the free volumes of the bionanocomposite films. Overall, these green bionanocomposite films with remarkable properties provide very interesting alternatives to nonbiodegradable-based food packaging.

The feasibility of biocomposite film of methylcellulose (MC) and crosslinker glutaraldehyde (GA) with extracted murta fruit (MU) was evaluated by Dicastillo et al. [143]. Based on the results, the addition of 20 wt.\% GA into MC/ MU film demonstrated about $55.57 \%$ reduction in swelling index, which was caused by the hydrophilicity reduction in crosslinked films as compared to the MC/MU/10 wt.\% GA film (105.60). The reduction in EB and modulus by $\sim 35 \%$ and $\sim 64.91 \%$, respectively, with $\sim 160 \%$ increment in TS for $\mathrm{MC} / \mathrm{MU} / 20$ wt.\% GA film was noted in contrast to the MC film (50\% EB; $855 \mathrm{MPa}$ modulus; $5 \mathrm{MPa}$ TS). These might be attributed to the strong interaction between matrix and crosslinker, which lowered the MC chain mobility, resulting in the enhancement of polymer strength, but reduced the flexibility of film. It was also emphasized that films that contained MU extract had reduced up to $99.90 \%$ of Listeria innocua (L. innocua) in regard to the no antimicrobial activity of MC film. The decreased swelling index and improved mechanical strength with antimicrobial properties were achieved as the concentration of GA increased.

The evaluation on bacterial cellulose/guar gum (BC/ GG)-based polyvinyl pyrrolidone/carboxymethyl cellulose (PVP/CMC) hydrogel film was made by Bandyopadhyay et al. [77]. It was noted that the combination of BC/GG and $\mathrm{PVP} / \mathrm{CMC}$ film showed the least reduction in EB by $2 \%$ with the second-best increment in TS of $6.15 \%$ and $5.62 \%$ modulus in contrast to the neat film $(23 \% \mathrm{~EB} ; 24.40 \mathrm{MPa}$ TS; $890 \mathrm{MPa}$ modulus). Among all films, about $24.43 \%$ reduction in contact angle proved that the lower side of PVP/ $\mathrm{CMC/BC/GG}$ film was suited as packaging exterior as a result of its better hydrophobicity to prevent water 
permeability than the PVP/CMC film $\left(61.40^{\circ}\right)$. Again, PVP/ $\mathrm{CMC} / \mathrm{BC} / \mathrm{GG}$ film presented the lowest WVP and OTR values in contrast to the control $\left(8.28 \times 10^{-13} \mathrm{~g}^{\bullet} \mathrm{m}^{-1} \mathrm{~h}^{-1} \mathrm{~Pa}^{-1}\right.$ WVP; $75 \mathrm{~cm}^{3} \cdot \mathrm{m}^{-2} \mathrm{day}^{-1} 0.1 \mathrm{MPa}^{-1}$ OTR) by $\sim 76.09 \%$ and $\sim 66.80 \%$, respectively. This might be attributed to the interactions between each component in the film, thereby improving the barrier properties. Interestingly, the introduction of BC/GG improved its biodegradation rate by about $7 \%$ relative to the neat film $(88 \%)$ after 28 days of burial. Therefore, PVP/CMC/BC/GG film was found to be a potential competitor for packaging application as it can prolong the shelf life of fresh berries up to 15 days of storage.

3.2. Gelatin. Gelatin (Figure 7) is one of the most published water-soluble proteinaceous materials, whereby it is obtained from animal collagen through the process of hydrolysis [144]. The production of gelatin as a raw material continues to grow due to the high consumer demand, particularly in food and beverage sector $(28.10 \%)$, nutraceuticals $(25.80 \%)$, pharmaceuticals $(21.00 \%)$, cosmeceuticals $(5.50 \%)$, photography $(13.50 \%)$, and others (6.10\%) [145]. Gelatin has gained great attention due to its unique characteristics, including low price, excellent film-forming ability, high binding potential with water and emulsifying properties, biodegradable, and also edible [146]. Unfortunately, the poor strength, durability, and low barrier effects are the main drawbacks for gelatin [147].

The development of gelatin-based film incorporated with papaya peel microparticles was evaluated by Crizel et al. to preserve lard [148]. The outcomes showed that the incorporation of $7.5 \mathrm{wt} . \%$ microparticles in gelation film significantly improved the mechanical properties by $124.93 \%$ (TS) and $125.85 \%$ (modulus) with the decrement of $171.63 \% \mathrm{~EB}$ versus the neat film (3.41 MPa TS; $1088.21 \mathrm{MPa}$ modulus; $338.30 \% \mathrm{~EB})$. The increased TS was undoubtedly referred to the protein-protein interaction in film with microparticles and higher dispersion of the particles inside the matrix, giving a good tension transfer. Notably, the microencapsulation of papaya peel (7.5 wt.\%) did not affect the WVP as it only increased to about $3.97 \%$ than the gelatin film

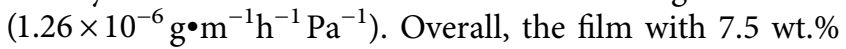
papaya peel microparticle powder was recommended as it demonstrated the optimum antioxidant activity with $31.51 \%$ among other loadings, over the gelatin film (6.71\%). The prepared film was found to be a good candidate for packaging application as the mentioned excellent properties were close to those of LDPE-based food packaging.

In addition, Soradech et al. investigated the edible surface coating, comprising $60 \mathrm{wt} . \%$ shellac and $40 \mathrm{wt} . \%$ gelatin [149]. A difference of $2.50 \%$ in weight loss was recorded between uncoated banana $(8.30 \%)$ and coated banana after 30 days of storage. Since the weight loss was closely associated with the firmness of banana, the firmness of coated banana $(46 \mathrm{~N})$ decreased around $52.17 \%$ in contrast to the $86.52 \%$ for uncoated banana $(45.41 \mathrm{~N})$ after 30 days of storage. The occurrence of depolymerization and deesterification of protopectin in the middle lamella of the cell walls were the main mechanisms, which contributed to the softening of the cell walls. As compared to the uncoated ones $\left(6.54 \log \mathrm{CFU} \cdot \mathrm{g}^{-1}\right)$, the banana coated with the composite film presented the best properties in which the reduction in molds and yeasts was achieved up to $\sim 38.84 \%$ at $25^{\circ} \mathrm{C}$ after 30 days of storage. In conclusion, the utilization of edible coating film was proven to be successful in extending the life span of banana.

Oliveira et al. discussed the integration of cashew gum (CG) and gelatin (G) films in the making of detergent pockets, dissolvable films, and fertilizer encapsulants [150]. Enhanced barrier properties were noted with higher content of gelatin, but 5 wt.\% G/5 wt.\% CG exhibited superior water vapor barrier than the control film $\left(1.35 \times 10^{-6} \mathrm{~g}^{\circ} \mathrm{m}^{-1} \mathrm{~h}^{-1} \mathrm{~Pa}^{-1}\right)$, which was reduced by $14.07 \%$ owing to the film compaction without pore formation. Conversely, the synergistic effect of $2.5 \mathrm{wt} . \% \mathrm{G} / 5 \mathrm{wt} . \%$ CG presented the highest flexibility of material with up to $114.03 \%$ EB among others, in contrast to the neat film (0.87\%). Thermal stability indicated a slight decrease of around $5.28 \%$ for the G/CG film than the gelatin film $\left(T_{d}\right.$ : $341.20^{\circ} \mathrm{C}$ ). As expected, the highest $\mathrm{CO}_{2}$ production of the $\mathrm{G} /$ CG film (311.11\%) after 22 days of biodegradable test indicated higher biodegradation rate as compared to the gelatin film ( $9 \mathrm{~mL} \mathrm{CO}_{2}$ production). These clarified that the use of G/CG film was discovered to be helpful as it showed higher ability in improving the biodegradation of final products.

Huang et al. evaluated the influence of electron beam irradiation on the antioxidants of bamboo leaves $(\mathrm{AOB})$ and fish gelatin (FG)-based films [151]. As compared to the unirradiated FG/AOB film (8.30 MPa TS; 64\% EB), $7 \mathrm{kGy}$ of FG/AOB film had maximum TS and minimum EB, as measured by $54.22 \%$ increment and $14 \%$ decrement, respectively. These behaviors were related to the intermolecular interaction and the formation of crosslinks that prevent the mobility of polymeric chains as a consequence of a denser structure formation after irradiation. Meanwhile, the FG/AOB film at $7 \mathrm{kGy}$ resulted in higher increment in WVP with $81.82 \%$ in accordance with $33.60 \%$ reduction in contact angle relative to the unirradiated film $\left(1.10 \times 10^{-6} \mathrm{~g}^{\circ} \mathrm{m}^{-1} \mathrm{~h}^{-1} \mathrm{~Pa}^{-1} 125^{\circ}\right)$. The higher humidity conditions $(\sim 100 \%)$ were the reason for these results, whereas the formation of a new bond after irradiation and increasing polarity on the film surface contributed to the lowered contact angle. Notably, the highest thermal stability for FG/ AOB film ( $7 \mathrm{kGy}$ ) was referred to the intermolecular or intramolecular interactions between FG and $\mathrm{AOB}$ with the aid of irradiation.

3.3. Polylactic Acid (PLA). Polylactic acid (PLA), which is also known as polylactide, represents the most promising biopolymer not only in the academic sector, but also in the plastic industry, whereby it is already commercialized in the form of pure or blended polymers (i.e., food packaging) to meet the need for sustainable green composites [152-154]. Apart from breaking down into smaller molecular weight by the presence of microorganism in the soil, the lactic acid monomers of PLA can also be produced via the fermentation 
process of renewable sources, which are obtained from corn, sugar, potatoes, and beet $[152,155]$. The properties of PLA (Figure 7) such as good mechanical strength, biocompatibility, abundance, and environmentally friendly make it worthy of a massive study in PLA. However, brittleness, low thermal stability, and low barrier properties restrict its direct utilization in food packaging applications [156-158].

The synergistic effect of $1 \mathrm{wt} . \% \mathrm{ZnO}$ nanoparticles and $0.5 \mathrm{wt} . \% \mathrm{Ag}$ nanoparticles in pure PLA film was explored by $\mathrm{Chu}$ et al. [159]. It was pointed out that the PLA/Ag/ZnO nanocomposite increased by $6.87 \% \mathrm{~EB}$ and decreased by about $41.06 \%$ and $29.32 \%$ for TS and modulus, respectively, than pure PLA $(5.35 \% \mathrm{~EB} ; 47.48 \mathrm{MPa}$ TS; $3118.79 \mathrm{MPa}$ modulus). These behaviors might relate to the incorporation of antimicrobial agents, which decreased the interactions between PLA chains and improved the mobility of PLA chains. The WVP of the PLA/Ag/ZnO nanocomposite $\left(6.84 \times 10^{-8} \mathrm{~g}^{\bullet} \mathrm{m}^{-1} \mathrm{~h}^{-1} \mathrm{~Pa}^{-1}\right)$ was better than those of pure PLA $\left(6.08 \times 10^{-8} \mathrm{~g}^{\circ} \mathrm{m}^{-1} \mathrm{~h}^{-1} \mathrm{~Pa}^{-1}\right)$, owing to the hydrophilic properties of $\mathrm{ZnO}$ nanoparticles. Notably, the PLA nanocomposite showed good antimicrobial activity against $E$. coli in contrast to the no antimicrobial properties of control film. As presented by Altan et al., the incorporation of carvacrol in PLA fibers $\left(T_{d}: 346^{\circ} \mathrm{C}\right)$ had increased thermal stability by about $8.96 \%$ due to the formation of hydrogen bonding between PLA chains and carvacrol molecules [160]. Meanwhile, the addition of carvacrol did not influence the thermal stability of zein fibers. The study also highlighted that carvacrol-loaded electrospun zein and PLA fibers were promising alternatives in extending the shelf life of bread as it could inhibit $99.60 \%$ and $91.30 \%$ of the growth of mold and yeast, respectively, at $20 \mathrm{wt} . \%$ carvacrol content.

The preparation of PLA films incorporated with microcrystalline cellulose (MCC) derived from the wood pulp was carried out by Kale et al. [161]. The WVTR was $35.20 \mathrm{~g} \cdot \mathrm{m}^{-2} \mathrm{day}^{-1}$ for the neat PLA film and increased slightly by $36.50 \mathrm{~g}^{\bullet} \mathrm{m}^{-2}$ day $^{-1}$ for the composite containing 2 wt. $\%$ MCC. Meanwhile, the film with 0.1 wt.\% MCC had the lowest WVTR value $\left(35.50 \mathrm{~g}^{\circ} \mathrm{m}^{-2}\right.$ day $\left.^{-1}\right)$. This might be due to the agglomeration of MCC particles in the PLA matrix, which provides a few void spaces, allowing more rapid permeation. As compared to the MCC loadings, 2 wt.\% MCC obtained an optimum increment of $1.92 \%$ and $23.61 \%$ for TS and modulus, respectively, with $1.94 \%$ decrement in EB than the PLA film (26.04 MPa TS; $288 \mathrm{MPa}$ modulus; 9.53\% EB). The increased TS and stiffness of composite were related to the lowered EB. Interestingly, the degradation rate of composite films increased in line with MCC loadings. PLA demonstrated four main stages of degradation (water absorption, ester cleavage forming oligomers, oligomer fractions of solubilization, and diffusion of soluble oligomers by bacteria). The presence of 2 wt.\% MCC was found to promote the biodegradation rate of PLA composite up to $448.00 \%$ in contrast to the PLA film after 90 days of burial. Therefore, this study seems encouraging for the application of PLA/MCC composite films for sustainable food packaging.

Villegas et al. investigated the effect of thymol and cinnamaldehyde on PLA film and PLA loaded with $5 \mathrm{wt} . \%$ organoclay Cloisite 30B (C30B) via supercritical impregnation using carbon dioxide $\left(\mathrm{scCO}_{2}\right)$ [162]. As a

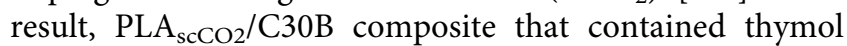
showed the lowest modulus and TS, which was reduced by $77.78 \%$ and $50 \%$, respectively, in contrast to the neat PLA (2250 MPa modulus; $12 \mathrm{MPa}$ TS). This can be explained by the plasticization effect of thymol, which reflected the decrease in both testings. However, the highest modulus of PLA/C30B composite confirms that organoclay can act as a reinforcing effect other than the good affinity between the $\mathrm{C} 30 \mathrm{~B}$ and the PLA matrix. It seems that all composites were applicable for food packaging purposes as the contact angle values were higher than $65^{\circ}$, which indicated the hydrophobic properties. Surprisingly, the impregnated films with both active compounds showed superior antimicrobial activity against $E$. coli and $S$. aureus with the concentration of 17 wt.\% thymol and 12 wt.\% cinnamaldehyde. It was found that all the composites were fully composted, evident by $90 \%$ of disintegration in less than 14 days.

In another study, Rezaeigolestani et al. improved the properties of PLA composites by introducing Zataria multiflora Bioss essential oil (ZME), propolis ethanolic extract (PEE), and cellulose nanofiber (CNF) to preserve vacuum-packed cooked sausages [163]. It was found that the PLA composite with only CNF demonstrated an increment of $32.92 \%$ and $20 \%$ for TS and modulus, respectively, with $9.70 \%$ decrement in EB in regard to the neat PLA (16.10 MPa TS; $1000 \mathrm{MPa}$ modulus; $49.30 \% \mathrm{~EB})$. The ability of CNF to produce tighter and more brittle composite simultaneously was the reason for these obtained results. In fact, the addition of ZME and PEE made stiff polymers (like PLA) more flexible due to the plasticization effect of additive in the matrix. As a result, the reduction of $27.95 \%$ TS and $28 \%$ modulus with an increment of $13.90 \%$ EB was noted in the case of PLA/1 v/v.\% ZME/CNF/PEE composite film. The incorporation of $0.5 \mathrm{v} / \mathrm{v} . \% \mathrm{ZME}$ and $2 \mathrm{v} / \mathrm{v} . \%$ PEE to the neat PLA $\left(6.44 \times 10^{-14} \mathrm{~g}^{\circ} \mathrm{m}^{-1} \mathrm{~h}^{-1} \mathrm{~Pa}^{-1}\right)$ had reduced the WVP by $11.17 \%$ due to the hydrophobic properties of essential oils. Interestingly, PLA/1 v/v.\% ZME/PEE composite could prolong the shelf life of sausages to more than 40 days, relating to the best antibacterial activity of the composite. Therefore, the superior reinforcing function of natural antimicrobial substances will expand the application of PLAbased composites as replacements for traditional petrochemical plastics, especially for food packaging applications.

3.4. Polyhydroxybutyrate (PHB). Polyhydroxybutyrate ( $\mathrm{PHB})$ is a thermoplastic biopolyester derived from renewable resources by bacterial synthesis and one of the members of polyhydroxyalkanoate (PHA) family [164]. Currently, the use of PHB incorporated with antioxidant and antifungal agents could be a means to extend the shelf life of refrigerated food [165]. PHB (Figure 7) is gaining increasing attention due to its excellent moisture barrier, mechanical performance, crystallinity, and biocompatibility and is naturally compostable under both aerobic and anaerobic conditions $[164,166]$. These particular characteristics exhibit similar end-use properties with nonbiodegradable-based food packaging, thereby are potentially suitable to replace 
the conventional plastics. However, it is still expensive and quite brittle for further uses $[166,167]$.

Manikandan et al. described the fabrication of PHBbased film with graphene nanoplatelets (GNPs) [168]. They stated that the insertion of 0.7 wt.\% GNP in PHB film demonstrated the best barrier properties, evident by the reduction of about $56.92 \%$ for WVP than the pristine film $\left(1.50 \times 10^{-10} \mathrm{~g} \bullet \mathrm{m}^{-1} \mathrm{~h}^{-1} \mathrm{~Pa}^{-1} \mathrm{WVP}\right)$. The insertion of impermeable GNP could form a tortuous structure inside the matrix and thus reduced the permeability. These results were closely related to the extended shelf life of potato chips and milk until 245 days and 26 days, versus 60 days and 6 days for the control, respectively. Comparing the neat PHB (4.50 MPa TS; $15 \% \mathrm{~EB})$, the TS was increased by $98 \%$, whereas EB was decreased by $2.80 \%$ with 0.7 wt.\% insertion of graphene. These could be explained by the uniform dispersion of graphene, which resulted in higher TS, while the high brittleness of nanofillers contributed to the lowered EB. Importantly, the $20 \%$ reduction in biodegradation was revealed by the nanocomposites after 30 days of burial as compared to the PHB film (100\%) due to the antimicrobial effect of graphene in nanocomposite.

The modification of PHB film with thermoplastic starch (TPS), organically modified montmorillonite (OMMT), and eugenol (Eug) was evaluated by Garrido-Miranda et al. [165]. The thermal stability study indicated that the presence of additives did not significantly influence the degradation temperature of $\mathrm{PHB}$ film $\left(T_{d}: 299.20^{\circ} \mathrm{C}\right)$. Moreover, the modulus was decreased by $24.68 \%$ for the PHB/TPS film, while it was increased by $12.82 \%$ with the addition of OMMT as compared to pure PHB (1560 MPa). The existence of OMMT as reinforcing agent was responsible for improving the TS of bionanocomposite. The decline in TS by $45.45 \%$ for the PHB/TPS film and $38.84 \%$ for the bionanocomposites film was observed in contrast to the PHB film $(24.20 \mathrm{MPa})$, relating to the incompatibility and lower interfacial adhesion between the added polymers. The incorporation of Eug $(2.5$ wt.\% and 3 wt.\% $)$ in bionanocomposites presented the optimum antioxidant activity with more than $90 \%$ in contrast to $5.07 \%$ PHB/TPS film and $2.35 \%$ bionanocomposites (without Eug). As compared to the other films, the bionanocomposites with eugenol successfully inhibited the growth of Botrytis cinerea, corresponding to the highest antioxidant activity.

Ma et al. compared the performance of plasticizers, namely mono-caprylin glycerate (GMC) and glycerol monolaurate (GML), in PLA/PHB blend film [169]. The introduction of GMC and GML (both 0.5 wt.\%) had increased the TS by $39.29 \%$ and $43.83 \%$, but in the case of EB, both films showed a reduction with $6.71 \%$ and $7.90 \%$, respectively, than the neat film (30.80 MPa TS; $13.60 \% \mathrm{~EB})$. These might be attributed to the diffusion of plasticizer and cinnamaldehyde (CIN) into the amorphous region of PLA/ PHB polymeric chain, which resulted in higher TS, whereas the simultaneous action of increasing intermolecular force and reducing slippage led to a lowered EB. In contrast to the control $\quad\left(22.30 \mathrm{~g}^{\circ} \mathrm{m}^{-2} \mathrm{day}^{-1} \quad\right.$ WVTR; $3.78 \times 10^{-13}$ $\mathrm{cm}^{3} \mathrm{~cm} \cdot \mathrm{cm}^{-2} \mathrm{~s}^{-1} \mathrm{~Pa}^{-1} \mathrm{OP}$ ), a statistical increase in WVTR and $\mathrm{OP}$ for both films was presented, evident by $211.66 \%$;
$17.20 \%$ (GMC) and 248.43\%; 33.07\% (GML), respectively, owing to the presence of the aldehyde group in CIN for each film. Interestingly, the shelf life of salmon dices packed with the PLA/PHB/GML film was prolonged up to 17 days in contrast to the deterioration of salmon dices packed with the PLA/PHB/GMC film after 15 days of storage.

Zhao et al. improved the properties of tomato sauce tray by introducing natural rubber (NR) in poly(3-hydroxybutyrate-co-3-hydroxyvalerate) (PHBV) [170]. The optimal $\mathrm{PHBV} / \mathrm{NR}$ blend was obtained at $15 \mathrm{wt} \%$ rubber, $3 \mathrm{phr}$ peroxide, and $4.2 \mathrm{phr}$ coagent loading with $28.10 \mathrm{MPa}$ TS. The study stated that the reduction in TS at higher rubber loading might be due to the softening effect of rubber. Conversely, the higher TS in line with higher coagent loading was responsible for improving peroxide crosslinking efficiency, which led to an increased polymer strength. Meanwhile, the occurrence of polymeric chain scission and poor crosslinking efficiency were the reasons that TS was not affected by the added peroxide. The WVTR of the blend $\left(38.90 \mathrm{~g} \bullet \mathrm{m}^{-2} \mathrm{day}^{-1}\right)$ was also comparable to the use of PP-

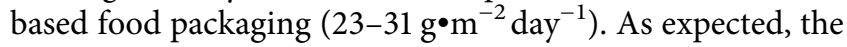
blend biodegradation rate was decreased by $9.90 \%$ than neat PHBV (24.70\%), owing to the higher molecular weight of NR. Therefore, the development of PHBV/NR blend was considered as an efficient production to replace and compete with synthetic polymer packaging.

3.5. Polycaprolactone (PCL). Polycaprolactone (PCL) is a synthetic biopolymer of aliphatic polyester synthesized by the ring-opening polymerization of $\varepsilon$-caprolactone [171]. It has been widely used as a suitable biomaterial thanks to its great biocompatible, biodegradable, low-set processing temperature $\left(60^{\circ} \mathrm{C}\right)$, superior strength, and good barrier properties [172]. Due to these reasons, PCL (Figure 7) is the most commonly used polymer based on food packaging, which was reported by Khalid et al. [173]. Nonetheless, its low barrier properties and lack of mechanical strength are the weakness of PCL [174].

The fabrication of acetylated hemicellulose (AH)nanocellulose (ACNC) films coated with PCL film was evaluated by Mugwagwa and Chimphango [175]. As compared to the PCL film (13.61 MPa TS; $43.90 \% \mathrm{~EB}$; $280.30 \mathrm{MPa}$ modulus), the TS and EB were decreased by $50.62 \%$ and $27.89 \%$, respectively, whereas the increase in modulus by $19.63 \%$ was recorded for PCL-coated AHACNC film. Interestingly, the modulus of coated PCL film (335.33 MPa) was close to that of the LDPE film (244.46 MPa). However, there was no significant difference in terms of wettability properties between uncoated and coated PCL films. It was worth to know that the introduction of polyphenol in AH-ACNC/PCL film was helpful in increasing the antioxidant activity. As a result, the fatty food simulant $\left(40^{\circ} \mathrm{C}\right)$ recorded the highest antioxidant activity, which was caused by the highest discharge of polyphenols from the films over the other simulants. Therefore, the integrity of AH-ACNC/PCL film as active packaging has huge potential to substitute LDPE-based food packaging. 
Ahmed et al. found that the combination of $\mathrm{ZnO}$ nanoparticles and clove essential oil (CEO) inside polylactide/polyethylene glycol/polycaprolactone (PLA/PEG/PCL) blend film could maintain the TS value (13.96 MPa) with a significant improvement of about $136.10 \% \mathrm{~EB}$ in contrast to the blend film (13.97 MPa TS; $25.48 \% \mathrm{~EB}$ ) [176]. The finer nanoparticle distribution and lower interfacial energy between matrix and nanoparticles resulted in higher TS. Meanwhile, the plasticization effect of CEO improved the EB of nanocomposite film. The synergistic effect of $\mathrm{ZnO}$ and CEO had reduced the WVP of the base film by around $78.41 \%$ than the control film $\left(5.65 \times 10^{-9} \mathrm{~g}^{\bullet} \mathrm{m}^{-1} \mathrm{~h}^{-1} \mathrm{~Pa}^{-1}\right)$. About $5.53 \%$ reduction in degradation temperature was noted, which indicated that the control film $\left(148.40^{\circ} \mathrm{C}\right)$ was more thermally stable than PLA/PEG/PCL/ZnO/CEO film. The enhanced flexibility of polymeric chains as a consequence of plasticizing effect was the main factor that reduced the thermal stability of nanocomposite film. After seven days of incubation, the combination of $3 \mathrm{wt} . \% \mathrm{ZnO}$ and $25 \mathrm{wt} . \%$ CEO was found to give the highest inhibition of $S$. aureus and complete inhibition of $E$. coli associated by the effect of active compound eugenol from $\mathrm{CEO}$ with the $\mathrm{ZnO}$ in contrast to no antimicrobial properties of control film. Overall, the prepared nanocomposite film was the best candidate for scrambled egg packaging.

Figueroa-Lopez et al. assessed the performance of multilayer systems, which consisted of gelatin (GEL) and electrospun PCL incorporated with black pepper oleoresin (OR) [177]. As compared to PCL film $\left(\mathrm{T}_{d}: 350^{\circ} \mathrm{C}\right)$, the PCL/ GEL/PCL film experienced an increase in thermal stability by $5.71 \%$ when incorporated with active coating (oleoresin). The study also stated that the WVP was increased by $540.43 \%$ for the PCL/GEL/PCL film, while (PCL + OR)/ $\mathrm{GEL} /(\mathrm{PCL}+\mathrm{OR})$ film was significantly increased by $1793.62 \%$, as compared to the PCL film

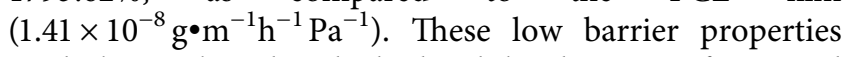
might be attributed to the hydrophilic character of GEL and the formation of a less continuous-film structure after adding OR, which led to higher permeation. However, the incorporated OR decreased the mechanical strength by $4.81 \%$ TS and $15.63 \%$ modulus with $1.90 \%$ increment of EB, in contrast to the PCL/GEL/PCL film (31.20 MPa TS; $15.50 \%$ EB; $883 \mathrm{MPa}$ modulus). The multilayer system that contained GEL, PCL, and OR provided a strong antimicrobial behavior toward S. aureus after 10 days of storage.

Wang et al. prepared antimicrobial food packaging, which was composed of PCL/chitosan film incorporated with grapefruit seed extract (GFSE) [178]. The introduction of 7 wt.\% GFSE in pristine film reduced the mechanical strength by $14.20 \%$ TS, $27.57 \% \mathrm{~EB}$, and $19.48 \%$ modulus than the neat film (13.31 MPa TS; $421.80 \%$ EB; $364.23 \mathrm{MPa}$ modulus). The decline in mechanical properties was undoubtedly related to the poor interfacial adhesion between matrix and GFSE and thus weakened the TS and EB, but in the case of modulus, the plasticization effect of glycerol in GFSE led to lower stiffness of polysaccharide film base. Among all the films, GFSE with 13 wt.\% was suggested for further use, as it presented the optimum antimicrobial activity. The complete inhibition of E. coli and no mold growth were presented by salmon and bread samples, respectively, which were packed in PCL/chitosan/GFSE film as compared to the $\mathrm{PCL} /$ chitosan film after seven days of storage. As a conclusion, the synergistic effect of polymers was found to have a higher potential to enhance film properties in regard to the use of each polymer alone.

3.6. Polybutylene Succinate (PBS). Polybutylene succinate (PBS) can be synthesized from polycondensation reaction of 1,4-butanediol with succinic acid [179]. PBS is a special candidate for the new development of bio-based food packaging due to the results of low cost, good processability, improved thermal stability, and chemical resistance [180]. Interestingly, the ester bond in PBS structure (Figure 7) can be chemically degraded by water or in the landfill through the action of microorganisms, in addition to the mechanical properties similar to commercially used PE and PP materials [181]. Despite those attractive properties, their high light penetration and expensive material along with insufficient water vapor barrier restrain its use in the food industry [182].

Ayu et al. examined the effectiveness of PBS blend with five modifications of tapioca starch (A, B, C, D, and E) [183]. The incorporation of starch D increased the TS by $21.03 \%$ owing to the high crystallinity of amylose content as compared to the starch E/PBS blend (14.98 MPa) at $40 \mathrm{wt} . \%$ starch loading. The lowest TS can be explained by the presence of high chain branches of amylopectin found in starch E/PBS blend. Generally, increasing the starch loading could lead to the weakening structure of the blend because of more void formation in the blend. In contrast, the rigidity of all blends was improved with higher concentrations of starch. Overall, the optimum loading for all types of starch should be less than $50 \mathrm{wt} . \%$ to achieve good tensile strength. Based on the starch types, the reduction in thermal stability was noted, but the high crystallinity of starch A, B, C, and D/ PBS blends revealed excellent thermal stability. To conclude, starch A, B, C, and D/PBS blends were proposed for food wrap and food container applications, whereas PBS/starch D blend was suitable for grocery plastic bags.

Recently, Wattanawong et al. assessed the fabrication of PBS film with the introduction of silver-loaded zeolite [184]. Based on the types, the silver Zeolite Socony Mobil-5 (ZSM5) was the best filler as it demonstrated the superior antibacterial activities toward E. coli and S. aureus. The incorporation of $0.5 \mathrm{wt} . \%$ AgZSM-5 into PBS film was sufficient to inhibit about $99.90 \%$ bacteria after $24 \mathrm{~h}$ incubation, relating to the bactericidal effect by silver ion. In contrast, the neat PBS presented $25 \%$ reduction in S. aureus with no antibacterial activity toward E. coli. The presence of outer membrane layer of bacteria should be considered as it can easily absorb the succinic acid, resulting in the bacterial cell damage. Overall, PBS/0.5 wt\% ZSM-5 film was found to be the optimum as it showed the lowest reduction of around $14.15 \%$ TS and $10.61 \%$ modulus with the highest EB by $8.81 \%$ relative to the neat PBS $(47.29 \mathrm{MPa}$ TS; $406.45 \mathrm{MPa}$ modulus; $442.49 \% \mathrm{~EB}$ ).

The fabrication of antimicrobial packaging from PBS and thymol was investigated by Petchwattana and Naknaen 
TABLE 3: Biodegradable composite-based food packaging.

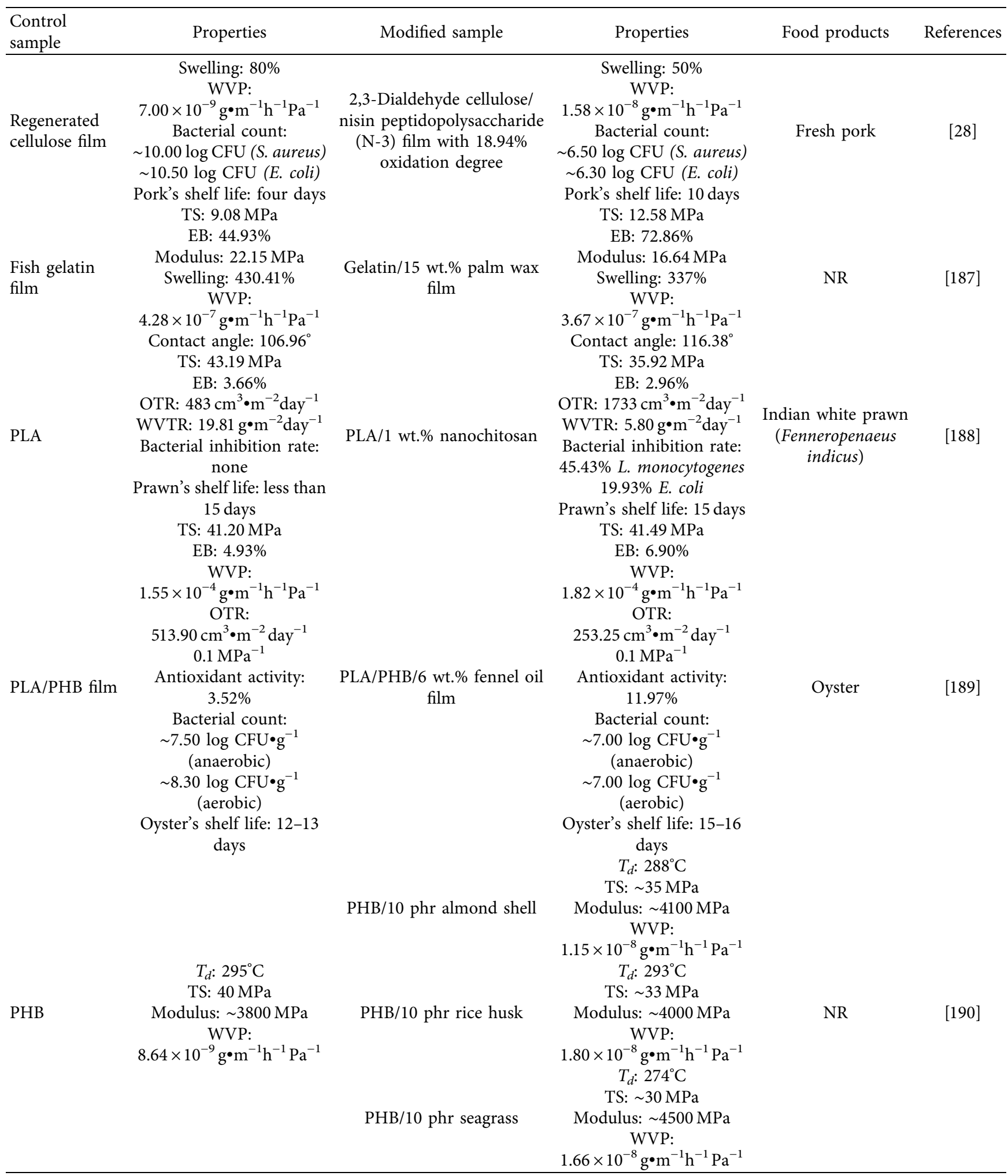


TABLE 3: Continued.

\begin{tabular}{|c|c|c|c|c|c|}
\hline $\begin{array}{l}\text { Control } \\
\text { sample }\end{array}$ & Properties & Modified sample & Properties & Food products & References \\
\hline $\begin{array}{l}\text { Chitosan/PCL } \\
\text { fibrous mat }\end{array}$ & $\begin{array}{c}T_{d}: 204.70^{\circ} \mathrm{C} \\
\text { TS: } 14 \mathrm{MPa} \\
\text { EB: } 26.60 \% \\
\text { Modulus: } 268.0 \mathrm{MPa} \\
\text { WVP: } \\
1.79 \times 10^{-7} \mathrm{~g}^{\circ} \mathrm{m}^{-1} \mathrm{~h}^{-1} \mathrm{~Pa}^{-1} \\
\text { Contact angle: } 119.10^{\circ} \\
\text { Bacterial inhibition rate: } \\
\text { none }\end{array}$ & $\begin{array}{l}\text { Chitosan/PCL/5 wt.\% } \\
\text { oregano essential oil (OEO) } \\
\text { composite fibrous mat }\end{array}$ & $\begin{array}{c}T_{d}: 235.90^{\circ} \mathrm{C} \\
\text { TS: } 7.62 \mathrm{MPa} \\
\text { EB: } 33.36 \% \\
\text { Modulus: } 181 \mathrm{MPa} \\
\text { WVP: } \\
3.69 \times 10^{-7} \mathrm{~g}^{-1} \mathrm{~m}^{-1} \mathrm{~h}^{-1} \mathrm{~Pa}^{-1} \\
\text { Contact angle: } 114.63^{\circ} \\
\text { Bacterial inhibition rate: } \\
52.72 \% \text { S. aureus } \\
41.06 \% \text { L. monocytogenes } \\
49.37 \% \text { S. enteritidis } \\
40.47 \% \text { E. coli }\end{array}$ & NR & [191] \\
\hline $\begin{array}{l}\text { PBSA/(90 wt. } \% \\
\text { PBS+ } 10 \text { wt. } \% \\
\text { PBSA) film }\end{array}$ & 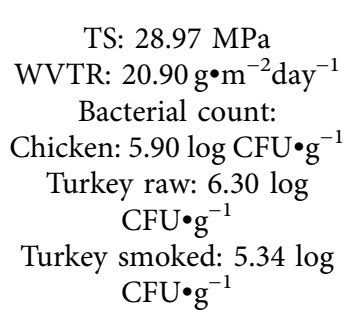 & $\begin{array}{c}\text { PBSA/(80 wt. } \% \text { PBS + } 10 \\
\text { wt. } \% \text { PBSA + } 10 \text { wt. } \% \text { talc }) \\
\text { film }\end{array}$ & $\begin{array}{c}\text { TS: } 34.87 \mathrm{MPa} \\
\text { WVTR: } 21 \mathrm{~g}^{-2} \mathrm{day}^{-1} \\
\text { Bacterial count: } \\
\text { Chicken: } 7.23 \mathrm{log} \\
\text { CFU•g } \\
\text { Turkey raw: } 7.46 \mathrm{log} \\
\text { CFU・g } \\
\text { Turkey smoked: } 6.08 \mathrm{log} \\
\text { CFU•g }\end{array}$ & $\begin{array}{c}\text { Chicken raw breast, } \\
\text { turkey raw breast, } \\
\text { and turkey smoked } \\
\text { breast }\end{array}$ & [181] \\
\hline $\begin{array}{l}\text { Cassava starch/ } \\
\text { chitosan }\end{array}$ & $\begin{array}{c}\text { TS: } 8.98 \mathrm{MPa} \\
\text { EB: } 101 \% \\
\text { Bacterial count: } \\
\text { Chicken: } 5.90 \log \mathrm{CFU} \bullet \mathrm{g}^{-1}\end{array}$ & $\begin{array}{l}\text { Cassava starch/chitosan } / 2 \\
\text { wt.\% lemongrass essential } \\
\text { oil (LEO) film }\end{array}$ & $\begin{array}{c}\text { TS: } 5.67 \mathrm{MPa} \\
\text { EB: } 25.55 \% \\
\text { Bacterial count: } \\
\text { Chicken: } 5.80 \mathrm{log} \\
\text { CFU・ }{ }^{-1}\end{array}$ & Chilies & [192] \\
\hline $\begin{array}{l}\text { Sodium } \\
\text { alginate }\end{array}$ & $\begin{array}{c}T_{d}: 225.89^{\circ} \mathrm{C} \\
\text { TS: } 29.20 \mathrm{MPa} \\
\text { EB: } 29.10 \% \\
\text { Modulus: } 677.30 \mathrm{MPa} \\
\text { WVTR: } \\
906.30 \mathrm{~g} \bullet \mathrm{m}^{-2} \mathrm{day}^{-1} \\
\text { WVP: } \\
1.44 \times 10^{-6} \mathrm{~g} \bullet \mathrm{m}^{-1} \mathrm{~h}^{-1} \mathrm{~Pa}^{-1}\end{array}$ & $\begin{array}{l}\text { Sodium alginate/0.5 wt.\% } \\
\qquad \mathrm{SiO}_{2}\end{array}$ & $\begin{array}{c}T_{d}: 224.78^{\circ} \mathrm{C} \\
\text { TS: } 30.6 \mathrm{MPa} \\
\text { EB: } 29.30 \% \\
\text { Modulus: } 809.60 \mathrm{MPa} \\
\text { WVTR: } \\
860.10 \mathrm{~g} \cdot \mathrm{m}^{-2} \mathrm{day}^{-1} \\
\text { WVP: } \\
1.51 \times 10^{-6} \mathrm{~g} \cdot \mathrm{m}^{-1} \mathrm{~h}^{-1} \mathrm{~Pa}^{-1}\end{array}$ & NR & [193] \\
\hline $\begin{array}{l}\text { PVA/gum } \\
\text { arabic }\end{array}$ & $\begin{array}{c}\text { TS: } 16.10 \mathrm{MPa} \\
\text { EB: } 26.60 \% \\
\text { Contact angle: } 60.50^{\circ} \\
\text { Bacterial inhibition rate: } \\
\text { none } \\
\text { Antioxidant activity: } 80 \%\end{array}$ & $\begin{array}{l}\text { PVA/20 wt. } \% \text { gum Arabic } \\
(\gamma \text {-ray irradiation })\end{array}$ & $\begin{array}{c}\text { TS: } 45.40 \mathrm{MPa} \\
\text { EB: } 23.50 \% \\
\text { Contact angle: } 80^{\circ} \\
\text { Bacterial inhibition rate: } \\
99.10 \% \text { S. aureus } \\
99.20 \% \text { P. aeruginosa } \\
\text { Antioxidant activity: } 60 \%\end{array}$ & Cheese & {$[194]$} \\
\hline Chitosan/PVA & $\begin{array}{c}T_{d}: 451.10^{\circ} \mathrm{C} \\
\text { TS: } 23.09 \mathrm{MPa} \\
\text { EB: } 220.84 \% \\
\text { Modulus: } 18.64 \mathrm{MPa} \\
\text { Contact angle: } 120^{\circ} \\
\text { WVP: lowest than } \\
2.93 \times 10^{-7} \mathrm{~g}^{\bullet} \mathrm{m}^{-1} \mathrm{~h}^{-1} \mathrm{~Pa}^{-1}\end{array}$ & $\begin{array}{c}\text { Chitosan/PVA/0.25 wt.\% } \\
\text { orange peel }\end{array}$ & $\begin{array}{c}T_{d}: 461.50^{\circ} \mathrm{C} \\
\text { TS: } 21.29 \mathrm{MPa} \\
\text { EB: } 240.79 \% \\
\text { Modulus: } 19.55 \mathrm{MPa} \\
\text { Contact angle: } 104.70^{\circ} \\
\text { WVP: } \\
2.93 \times 10^{-7} \mathrm{~g}^{\circ} \mathrm{m}^{-1} \mathrm{~h}^{-1} \mathrm{~Pa}^{-1} \\
\end{array}$ & NR & [195] \\
\hline
\end{tabular}

PLA, polylactic acid; PHB, polyhydroxybutyrate; PCL, polycaprolactone; PBS, polybutylene succinate; PBSA, polybutylene succinate-co-adipate; PVA, polyvinyl alcohol; Td, degradation temperature; WVP, water vapor permeability; WVTR, water vapor transmission rate; OTR, oxygen transmission rate; TS, tensile strength; EB, elongation at break; S. aureus, Staphylococcus aureus; L. monocytogenes, Listeria monocytogenes; S. enteritidis, Salmonella enteritidis; E. coli, Escherichia coli; NR, not reported.

[185]. The incorporation of 2 wt.\% and $10 \mathrm{wt} \%$ thymol recorded the lowest decrement of about $10.86 \%$ TS and the highest EB value of around 5.12\%, respectively, as compared to the pristine PBS (39.98 MPa TS; $17.46 \% \mathrm{~EB})$. The lowered TS can be explained by the plasticization effect originated from thymol, which made the PBS/thymol film less stiff than
PBS film. Meanwhile, the reduction in intermolecular forces between thymol and matrix resulted in higher elongation at higher rate. As compared to the control $(63.19 \mathrm{ml}$ mil $\bullet \mathrm{m}^{-2} \mathrm{day}^{-1} \mathrm{~atm}^{-1}$ ), the least increment of OTR by $3.69 \%$ with 2 wt.\% thymol made it more suitable for food packaging. In regard to the plasticization effect, the increase in 
amorphous segment in the PBS film resulted in higher oxygen permeability. It was interesting to note that $6 \mathrm{wt} \%$ and $10 \mathrm{wt} . \%$ of thymol were found to be optimum toward $S$. aureus and $E$. coli, respectively.

Negrin et al. studied the influence of irradiation toward PBS-based film and poly(butylene/thiodiethylene succinate) random copolymer (PBS-PTDGS) films [186]. The decreased thermal stability for all films with higher absorbed dose was due to the reduction in molecular number $\left(M_{\mathrm{n}}\right)$ caused by the degradation of polymer chains into shorter segments. The residual $M_{\mathrm{n}}$ of PBS film at $200 \mathrm{kGy}$ was statistically decreased by $50 \%$ in contrast to $20 \%$ residual $M_{\mathrm{n}}$ for $\mathrm{P}$ (BS60TDGS40). The PBS film (100 kGy) in water showed a $16.67 \%$ reduction (contact angle) as compared to the unirradiated PBS film $\left(90^{\circ}\right)$, thereby improving the wettability properties. Meanwhile, the wettability of PBS-based copolymers was in line with the absorbed doses, particularly in air. After 52 days of burial, the irradiated PBS film portrayed more resistance to degradation, which is equal to $77 \%$ (air) than $40 \%$ (water) at $100 \mathrm{kGy}$ as compared to $62 \%$ residual weight of neat PBS (0 kGy). Meanwhile, a slight improvement in biodegradation was shown by irradiated $\mathrm{P}$ (BS70TDGS30) copolymer in water (100 kGy) as compared to the treatment in air at the same dose. This proved that the utilization of gamma irradiation was very helpful in improving the biodegradation of PBS polymer.

To summarize, biodegradable materials have aroused as a sustainable alternative to lessen the dependency on nonbiodegradable-based plastics along with the development of a greener economy in regard to its biodegradable, biocompatible, renewable, and excellent properties. Based on the detailed analysis, it can be clearly seen that the modification of biodegradable materials has produced numerous candidates for food packaging, whereby the properties are comparable to nonbiodegradable counterparts. Table 3 lists the additional uses of biodegradable composites for food packaging application.

\section{Conclusion and Future Perspective}

This review summarizes the comparison on the performance of nonbiodegradable (PE, PP, PVC, PS, and PET) and biodegradable (cellulose, gelatin, PLA, PHB, PCL, and PBS)based composites for food packaging application. In this review, the important properties of biodegradation, mechanical strength, thermal stability, barrier properties, and antioxidant and antimicrobial or antibacterial activity were highlighted to fulfill the specification of food packaging. The issues, challenges, and suggestions regarding the production of food packaging were also discussed. The selection of polymers can sometimes be limited, but the improvement in the integrity of biodegradable-based food packaging with plant extracts, nanomaterials, or other types of polymers is suggested as these materials can complement each other, resulting in a far superior final product. In short, the utilization of biodegradable composites is highly beneficial for the food industry sector.

Despite the fact that many studies have shown that the nonbiodegradable composites can produce a much better food packaging, there is an urgent need for further studies on the use of biodegradable-based food packaging, which may be helpful to replace the use of conventional packaging. It cannot be denied that the lack of market demand might be due to the high cost of green packaging, but the fact that nonbiodegradable-based packaging takes up to thousand years to disintegrate and breakdown completely in natural environment requires in-depth case studies on how biodegradable materials can reduce the high treatment cost of plastic waste management and limited landfill sites. Therefore, the identification of biodegradable-based food packaging is essential to ensure that the final properties of prepared packaging exhibit similar end-use properties with those of commercial packaging.

A global public awareness on the development of green food packaging should also be implemented to initiate the environmentally friendly lifestyle. Even though the impacts on plastic waste accumulation were highlighted, information on the influence of these global issues toward humans and environment is still insufficient. In this context, the involvement of the government is suggested to restrict the use of commercial food packaging to increase the demand toward green packaging products at an industrial scale.

\section{Data Availability}

Not available.

\section{Conflicts of Interest}

The authors declare no conflicts of scientific and financial interest.

\section{Acknowledgments}

The authors would like to thank the Malaysian Nuclear Agency, Selangor, and the Department of Chemistry, Faculty Science and Technology, Universiti Kebangsaan Malaysia, for providing research facilities to conduct this research. This review and APC were funded by the Ministry of Higher Education, Malaysia, Grant Number FRGS/1/2019/STG01/ $\mathrm{UKM} / 02 / 8$.

\section{References}

[1] S. M. Al-Salem, A. Antelava, A. Constantinou, G. Manos, and A. Dutta, "A review on thermal and catalytic pyrolysis of plastic solid waste (PSW)," Journal of Environmental Management, vol. 197, pp. 177-198, 2017.

[2] L. Lebreton and A. Andrady, "Future scenarios of global plastic waste generation and disposal," Palgrave Communications, vol. 5, no. 1, pp. 1-11, 2019.

[3] E. F. Beitzen-Heineke, N. Balta-ozkan, and H. Reefke, "The prospects of zero-packaging grocery stores to improve the social and environmental impacts of the food supply chain," Journal of Cleaner Production, vol. 140, no. 3, pp. 1528-1541, 2017.

[4] Reuters, "Report: Malaysians Asia's biggest plastic consumers," 2020, https://www.nst.com.my/news/nation/2020/02/566374/ report-malaysians-asias-biggest-plastic-consumers. 
[5] O. Alam, M. Billah, and D. Yajie, "Characteristics of plastic bags and their potential environmental hazards," Resources, Conservation and Recycling, vol. 132, pp. 121-129, 2018.

[6] S. A. Kamaruddin, H. H. Rusli, K. N. A. Aziz, and M. A. Roslani, "Characteristics and distribution of microplastics in surface sediment of selat pulau tuba, langkawi, kedah," Malaysian Journal of Sustainable Environment, vol. 7, no. 2, pp. 139-160, 2020.

[7] D. Xanthos and T. R. Walker, "International policies to reduce plastic marine pollution from single-use plastics (plastic bags and microbeads): a review," Marine Pollution Bulletin, vol. 118, no. 1-2, pp. 17-26, 2017.

[8] A. Khoironi, H. Hadiyanto, S. Anggoro, and S. Sudarno, "Evaluation of polypropylene plastic degradation and microplastic identification in sediments at Tambak Lorok coastal area, Semarang, Indonesia," Marine Pollution Bulletin, vol. 151, pp. 110868-110910, 2020.

[9] L. K. Ncube, A. U. Ude, E. N. Ogunmuyiwa, R. Zulkifli, and I. N. Beas, "An overview of plastic waste generation and management in food packaging industries," Recycling, vol. 6, no. 1, pp. 1-25, 2021.

[10] Y. Peng, P. Wu, A. T. Schartup, and Y. Zhang, "Plastic waste release caused by COVID-19 and its fate in the global ocean," Proceedings of the National Academy of Sciences, vol. 118, no. 47, pp. 1-6, 2021.

[11] M. Rujnic-Sokele and A. Pilipovi, "Challenges and opportunities of biodegradable plastics: a mini review," Waste Management and Research, vol. 35, no. 2, pp. 132-140, 2017.

[12] K. S. Tumwesigye, J. C. Oliveira, and M. J. Sousa-gallagher, "New sustainable approach to reduce cassava borne environmental waste and develop biodegradable materials for food packaging applications," Food Packaging and Shelf Life, vol. 7, pp. 8-19, 2016.

[13] H. Kamaruddin, F. I. Razman, A. W. M. Nasir, and M. A. Sahmat, "Awareness in reducing single-use plastic: a case study of students in UKM," Opción, vol. 36, pp. 19101917, 2020.

[14] V. Koushal, R. Sharma, M. Sharma, R. Sharma, and V. Sharma, "Plastics: issues challenges and remediation," International Journal of Waste Resources, vol. 4, no. 1, pp. 1-6, 2014.

[15] M. K. F. D. Radzi, N. Muhamad, M. N. Akhtar, Z. Razak, and F. M. Foudzi, "The effect of kenaf filler reinforcement on the mechanical and physical properties of injection moulded polypropylene composites," Sains Malaysiana, vol. 47, no. 2, pp. 367-376, 2018.

[16] J. M. Soto, G. Blázquez, M. Calero, L. Quesada, V. Godoy, and M. Á. Martín-Lara, "A real case study of mechanical recycling as an alternative for managing of polyethylene plastic film presented in mixed municipal solid waste," Journal of Cleaner Production, vol. 203, pp. 777-787, 2018.

[17] K. Ragaert, L. Delva, and K. Van Geem, "Mechanical and chemical recycling of solid plastic waste," Waste Management, vol. 69, pp. 24-58, 2017.

[18] H. Ritchie and M. Roser, Plastic Pollution, 2018, https:// ourworldindata.org/plastic-pollution.

[19] P. Saklani, S. K. Das, and S. M. Singh, "A review of edible packaging for foods," International Journal of Current Microbiology and Applied Sciences, vol. 8, no. 7, pp. 2885-2895, 2019.

[20] N. Halonen, P. S. Palvolgyi, A. Bassani et al., "Bio-based smart materials for food packaging and sensors," Frontiers in Materials, vol. 7, pp. 1-14, 2020.
[21] N. Abdullahi, "Advances in food packaging technology-A review," Journal of Postharvest Technology, vol. 6, no. 4, pp. 55-64, 2019.

[22] S. A. M. Isa, R. Mohamed, H. Tahir, R. R. R. Mohamed, and R. Ahmad, "Tensile and antimicrobial properties of linear low density polyethylene (LLDPE) and chitosan blend," AIP Conference Proceedings, pp. 1-8, 2018.

[23] F. Mohanty and S. K. Swain, "Bionanocomposites for food packaging applications," in Nanotechnology Applications in Food, pp. 363-379, Elsevier Inc., Amsterdam, Netherland, 2017.

[24] A. Li, C. Zhang, and Y.-F. Zhang, "Thermal conductivity of graphene-polymer composites: mechanisms, properties, and applications," Polymers, vol. 9, no. 9, pp. 1-17, 2017.

[25] I. Gan and W. S. Chow, "Antimicrobial poly(lactic acid)/ cellulose bionanocomposite for food packaging application: a review," Food Packaging and Shelf Life, vol. 17, pp. 150-161, 2018.

[26] D. Yusufu, C. Wang, and A. Mills, "Evaluation of an 'After Opening Freshness (AOF)' label for packaged ham," Food Packaging and Shelf Life, vol. 17, pp. 107-113, 2018.

[27] A. Krishnamurthy and P. Amritkumar, "Synthesis and characterization of eco-friendly bioplastic from low-cost plant resources," SN Applied Sciences, vol. 1, no. 11, pp. 1-13, 2019.

[28] Y. Wu, Q. Li, X. Zhang, Y. Li, B. Li, and S. Liu, "Cellulosebased peptidopolysaccharides as cationic antimicrobial package films," International Journal of Biological Macromolecules, vol. 128, pp. 673-680, 2019.

[29] M. Yadav and F.-C. Chiu, "Cellulose nanocrystals reinforced $\kappa$-carrageenan based UV resistant transparent bionanocomposite films for sustainable packaging applications," Carbohydrate Polymers, vol. 211, pp. 181-194, 2019.

[30] M. El Achaby, Z. Kassab, A. Aboulkas, C. Gaillard, and A. Barakat, "Reuse of red algae waste for the production of cellulose nanocrystals and its application in polymer nanocomposites," International Journal of Biological Macromolecules, vol. 106, pp. 681-691, 2018.

[31] E. G. Fawal, H. Hong, X. Song et al., "Fabrication of antimicrobial films based on hydroxyethylcellulose and $\mathrm{ZnO}$ for food packaging application," Food Packaging and Shelf Life, vol. 23, pp. 1-7, 2020.

[32] A. K. Bharimalla, S. P. Deshmukh, N. Vigneshwaran, P. G. Patil, and V. Prasad, "Nanocellulose based polymer composites for applications in food packaging: future prospects and challenges," Polymer - Plastics Technology and Engineering, vol. 56, no. 8, pp. 1-71, 2017.

[33] K. Alirezalu, S. Pirouzi, M. Yaghoubi, M. Karimi-Dehkordi, S. Jafarzadeh, and A. M. Khaneghah, "Packaging of beef fillet with active chitosan film incorporated with $\mathcal{\varepsilon}$-polylysine: an assessment of quality indices and shelf life," Meat Science, vol. 176, pp. 1-9, 2021

[34] H. Yousefi, H.-M. Su, S. M. Imani, K. Alkhaldi, C. D. Filipe, and T. F. Didar, "Intelligent food packaging: a review of smart sensing technologies for monitoring food quality," ACS Sensors, vol. 4, no. 4, pp. 808-821, 2019.

[35] B. Melendez-Rodriguez, J. L. Castro-Mayorga, M. A. M. Reis et al., "Preparation and characterization of electrospun food biopackaging films of poly(3-hydroxybutyrate-co-3hydroxyvalerate) derived from fruit pulp biowaste," Frontiers in Sustainable Food Systems, vol. 2, no. 38, pp. 1-6, 2018.

[36] K. Saravanakumar, A. Sathiyaseelan, A. V. A. Mariadoss, H. Xiaowen, and M.-H. Wang, "Physical and bioactivities of biopolymeric films incorporated with cellulose, sodium 
alginate and copper oxide nanoparticles for food packaging application," International Journal of Biological Macromolecules, vol. 153, no. 153, pp. 207-214, 2020.

[37] U. H. Abdullah, I. Ahmad, A. Hamzah, and N. A. Rosli, "Kecekapan filem kanji/minyak kayu manis sebagai pembungkus makanan dengan sifat antimikrob," Sains Malaysiana, vol. 49, no. 8, pp. 1935-1945, 2020.

[38] L. G. Hong, N. Y. Yuhana, N. Y. Yuhana, and E. Z. E. Zawawi, "Review of bioplastics as food packaging materials," AIMS Materials Science, vol. 8, no. 2, pp. 166-184, 2021.

[39] C. Ndahebwa Muhonja, G. Magoma, M. Imbuga, and H. M. Makonde, "Molecular characterization of low-density polyethene (LDPE) degrading bacteria and fungi from dandora dumpsite, nairobi, Kenya," International Journal of Microbiology, vol. 2018, no. 7, 10 pages, Article ID 4167845, 2018.

[40] J. Zhang, W. R. Xu, Y. C. Zhang, X. D. Han, C. Chen, and A. Chen, "In situ generated silica reinforced polyvinyl alcohol/liquefied chitin biodegradable films for food packaging," Carbohydrate Polymers, vol. 238, pp. 116182-116186, 2020.

[41] H. U. Zaman and M. D. H. Beg, "Study on binary low-density polyethylene (LDPE)/thermoplastic sago starch (TPS) blend composites," Progress in Applied Science and Technology, vol. 11, pp. 53-65, 2021.

[42] N. Mohanan, Z. Montazer, P. K. Sharma, and D. B. Levin, "Microbial and enzymatic degradation of synthetic plastics," Frontiers in Microbiology, vol. 11, pp. 1-49, 2020.

[43] M. Nevoralova, M. Koutny, A. Ujcic et al., "Structure characterization and biodegradation rate of poly( $\varepsilon$-caprolactone)/starch blends," Frontiers in Materials, vol. 7, pp. 1-14, 2020.

[44] M. Y. Chan and S. C. Koay, "Biodegradation and thermal properties of crosslinked chitosan/corn cob biocomposite films by electron beam irradiation," Polymer Engineering \& Science, vol. 59, no. 1, pp. 59-68, 2018.

[45] A. Folino, A. Karageorgiou, P. S. Calabro, and D. Komilis, "Biodegradation of wasted bioplastics in natural and industrial environments: a Review," Sustainability, vol. 12, no. 15, pp. 1-37, 2020.

[46] A. P. Asiandu, A. Wahyudi, and S. W. Sari, "A review: plastics waste biodegradation using plastics-degrading bacteria," Journal of Environmental Treatment Techniques, vol. 9, no. 1, pp. 148-157, 2021.

[47] S. Ghatge, Y. Yang, J.-H. Ahn, and H.-G. Hur, "Biodegradation of polyethylene: a brief review," Applied Biological Chemistry, vol. 63, no. 27, pp. 1-14, 2020.

[48] I. Majid, M. Thakur, and V. Nanda, "Biodegradable packaging materials," in Reference Module Materials Science and Materials Engineering, pp. 1-11, Elsevier Inc., Amsterdam, Netherlands, 2018.

[49] A. K. Zykova, P. V. Pantyukhov, N. N. Kolesnikova, T. V. Monakhova, and A. A. Popov, "Influence of filler particle size on physical properties and biodegradation of biocomposites based on low-density polyethylene and lignocellulosic fillers," Journal of Polymers and the Environment, vol. 26, no. 4, pp. 1343-1354, 2018.

[50] S. Z. Rogovina, K. V. Aleksanyan, A. Y. Gorenberg, N. E. Ivanushkina, E. V. Prut, and A. A. Berlin, "Investigation of biodegradability of composites based on polyethylene and polysaccharides by independent methods," Mendeleev Communications, vol. 28, no. 1, pp. 105-107, 2018.
[51] V. Bulakh, N. Sova, B. Savchenko, and O. Sleptsov, "Degradation properties study of LDPE and plasticized starch composite blown film," Fibres and Textiles, vol. 25, no. 3, pp. 13-23, 2018.

[52] R. R. Ali, W. A. W. A. Rahman, R. M. Kasmaini et al., "Pineapple peel fibre biocomposite: characterisation and biodegradation studies," Chemical Engineering Transactions, vol. 56, pp. 1333-1338, 2017.

[53] Z. Mohamad and M. Z. H. Saadan, "Biodegradability and tensile properties of compatibilised polyethylene/rice bran film," Chemical Engineering Transactions, vol. 56, pp. 919924, 2017.

[54] F. Yang, H. Long, B. Xie et al., "Mechanical and biodegradation properties of bamboo fiber-reinforced starch polypropylene biodegradable composites," Journal of Applied Polymer Science, vol. 137, no. 20, pp. 1-8, 2019.

[55] U. K. Komal, V. Verma, T. Ashwani, N. Verma, and I. Singh, "Effect of chemical treatment on thermal, mechanical and degradation behavior of banana fiber reinforced polymer composites," Journal of Natural Fibers, vol. 17, no. 7, pp. 1026-1038, 2018.

[56] N. Dinh Vu, H. Thi Tran, and T. Duy Nguyen, "Characterization of polypropylene green composites reinforced by cellulose fibers extracted from rice straw," International Journal of Polymer Science, vol. 2018, no. 4, 10 pages, Article ID 1813847, 2018.

[57] S. B. Roy, R. A. Sengupta, and P. R. Shukla, "Biodegradability studies of bio-composites of polypropylene reinforced by potato starch," International Journal of Innovative Research in Science, Engineering and Technology, vol. 4, no. 3, pp. 1-11, 2015.

[58] A. Nourbakhsh, A. Ashori, and A. Kazemi Tabrizi, "Characterization and biodegradability of polypropylene composites using agricultural residues and waste fish," Composites Part B: Engineering, vol. 56, pp. 279-283, 2014.

[59] A. K. Chaudhary and R. P. Vijayakumar, "Synthesis of polystyrene/starch/CNT composite and study on its biodegradability," Journal of Polymer Research, vol. 27, no. 187, pp. 1-12, 2020.

[60] H. E. Ali and A. M. Abdel Ghaffar, "Preparation and effect of gamma radiation on the properties and biodegradability of poly(styrene/starch) blends," Radiation Physics and Chemistry, vol. 130, pp. 411-420, 2017.

[61] R. Siakeng, M. Jawaid, M. Asim, and S. Siengchin, "Accelerated weathering and soil burial effect on biodegradability, colour and textureof coir/pineapple leaf fibres/ PLA biocomposites," Polymers, vol. 12, no. 2, pp. 1-15, 2020.

[62] M. M. Pang, Y. Aaron, S. C. Koay, J. H. Low, H. L. Choo, and K. Y. Tshai, "Soil burial, hygrothermal and morphology of durian skin fiber filled polylactic acid biocomposites," $A d$ vances in Environmental Biology, vol. 13, no. 3, pp. 21-25, 2019.

[63] J. I. P. Singh, S. Singh, and V. Dhawan, "Mechanical and biodegradation behaviour of jute/polylactic acid green composites," Asian Journal of Engineering and Applied Technology, vol. 7, no. 2, pp. 52-57, 2018.

[64] O. Wilfred, Z. Fan, W. Wang et al., "Biodegradation of polylactic acid and starch composites in compost and soil," International Journal of Nano Research, vol. 1, no. 2, pp. 1-11, 2018.

[65] R. Gunti, A. V. Ratna Prasad, and A. V. S. S. K. S. Gupta, "Mechanical and degradation properties of natural fiberreinforced PLA composites: jute, sisal, and elephant grass," Polymer Composites, vol. 39, no. 4, pp. 1125-1136, 2016. 
[66] A. M. Avecilla-Ramírez, M. d. R. López-Cuellar, B. VergaraPorras, A. I. Rodríguez-Hernández, E. Vázquez-Núñez, and E. Vazquez-Nunez, "Characterization of poly-hydroxybutyrate/luffa fibers composite material," Bioresources, vol. 15, no. 3, pp. 7159-7177, 2020.

[67] F. Touchaleaume, R. Tessier, R. Auvergne, S. Caillol, S. Hoppe, and H. Angellier-Coussy, "Polyhydroxybutyrate/ hemp biocomposite: tuning performances by process and compatibilisation," Green Materials, vol. 7, no. 4, pp. 194-204, 2019.

[68] M. A. Gunning, L. M. Geever, J. A. Killion, J. G. Lyons, and C. L. Higginbotham, Polymer-Plastics Technology and Engineering, vol. 53, no. 12, pp. 1-14, 2014.

[69] J. S. Lyu, J.-S. Lee, and J. Han, "Development of biodegradable polycaprolactone film incorporated with an antimicrobial agent via an extrusion process," Scientific Reports, vol. 9, pp. 1-11, 2019.

[70] D. C. Borghesi, M. F. Molina, M. A. Guerra, and M. G. N. Campos, "Biodegradation study of a novel polycaprolactone-coffee husk composite film," Materials Research, vol. 19, no. 4, pp. 752-758, 2016.

[71] S. Cesur, C. Koroglu, and H. T. Yalcin, "Antimicrobial and biodegradable food packaging applications of polycaprolactone/organo nanoclay/chitosan polymeric composite films," Journal of Vinyl and Additive Technology, vol. 24, no. 4, pp. 1-12, 2017.

[72] L. N. Ludueña, A. Vázquez, and V. A. Alvarez, "Effect of the type of clay organo-modifier on the morphology, thermal/ mechanical/impact/barrier properties and biodegradation in soil of polycaprolactone/clay nanocomposites," Journal of Applied Polymer Science, vol. 128, no. 5, pp. 2648-2657, 2012.

[73] R. Neppali, V. Causin, C. Marega, R. Saini, M. Mba, and A. Marigo, "Structure, morphology, and biodegradability of poly $(\varepsilon$-caprolactone)-based nanocomposites," Polymer Engineering \& Science, vol. 51, no. 8, pp. 1489-1496, 2011.

[74] O. Platnieks, S. Gaidukovs, A. Barkane et al., "Bio-based poly(butylene succinate)/microcrystalline cellulose/nanofibrillated cellulose-based sustainable polymer composites: thermo-mechanical and biodegradation studies," Polymers, vol. 12, no. 7, pp. 1-20, 2020.

[75] Z. Huang, L. Qian, Q. Yin, N. Yu, T. Liu, and D. Tian, "Biodegradability studies of poly(butylene succinate) composites filled with sugarcane rind fiber," Polymer Testing, vol. 66, pp. 319-326, 2018.

[76] H. Anankaphong, D. Pentrakoon, and J. Junkasem, "Effect of rubberwood content on biodegradability of poly(butylene succinate) biocomposites," International Journal of Polymer Science, vol. 2015, Article ID 368341, 9 pages, 2015.

[77] S. Bandyopadhyay, N. Saha, U. V. Brodnjak, and P. Saha, "Bacterial cellulose and guar gum based modified PVP-CMC hydrogel films: characterized for packaging fresh berries," Food Packaging and Shelf Life, vol. 22, pp. 1-9, 2019.

[78] M. Alshabanat, "Morphological, thermal, and biodegradation properties of LLDPE/treated date palm waste composite buried in a soil environment," Journal of Saudi Chemical Society, vol. 23, no. 3, pp. 355-364, 2019.

[79] H. U. Zaman and R. A. Khan, "Improving the physicomechanical and degradable properties of thermoplastic polymer with modified starch blend composites for packaging applications," Progress in Applied Science and Technology, vol. 11, no. 3, pp. 1-8, 2021.

[80] B. Horvath, E. Mallinguh, and C. Fogarassy, "Designing business solutions for plastic waste management to enhance circular transitions in Kenya," Sustainability, vol. 10, no. 5, pp. 1-20, 2018.

[81] J. Jambeck, B. D. Hardesty, A. L. Brooks et al., "Challenges and emerging solutions to the land-based plastic waste issue in Africa," Marine Policy, vol. 96, pp. 256-263, 2018.

[82] P. Homayounpour, H. Jalali, N. Shariatifar, M. Amanlou, and A. Khanjari, "Protective effect of nanochitosan incorporated with free/nanoliposome cumin (Cuminum cyminum L.) aqueous extract on sardine fish," Journal of Aquatic Food Product Technology, vol. 29, no. 9, pp. 949-961, 2020.

[83] P. A. V. Freitas, R. R. A. Silva, T. V. de Oliveira, R. R. A. Soares, and N. F. F. Soares, "Biodegradable film development by nisin $\mathrm{Z}$ addition into hydroxypropylmethylcellulose matrix for mozzarella cheese preservation," International Journal of Food Studies, vol. 9, no. 2, pp. 360-372, 2020.

[84] M. E. Dominguez-Espinosa, A. Fuentes-Ruiz, A. ArreolaGonzalez et al., "Edible coating based on banana starch and chitosan for postharvest conservation of guava," Journal of Food Processing and Preservation, vol. 46, no. 1, pp. 1-14, 2021.

[85] X. Zhou, R. Cheng, B. Wang et al., "Biodegradable sandwicharchitectured films derived from pea starch and polylactic acid with enhanced shelf-life for fruit preservation," Carbohydrate Polymers, vol. 251, pp. 117117-117213, 2021.

[86] B. T. Ho, T. K. Roberts, and S. Lucas, "An overview on biodegradation of polystyrene and modified polystyrene: the microbial approach," Critical Reviews in Biotechnology, vol. 38, no. 2, pp. 308-320, 2018.

[87] N. Raddadi and F. Fava, "Biodegradation of oil-based plastics in the environment: existing knowledge and needs of research and innovation," The Science of the Total Environment, vol. 679, pp. 148-158, 2019.

[88] M. Z. Issa and A. N. F. Rahim, "The perceptions of plastic packaging usage to pack hot foods among food hawkers at night markets in Kuala Selangor, Malaysia," International Food Research Journal, vol. 25, pp. 75-78, 2018.

[89] J. Xu, W. Yang, C. Zhang, X. Dong, and Y. Luo, "Photooxidation and biodegradation of polyethylene films containing polyethylene glycol modified $\mathrm{TiO} 2$ as pro-oxidant additives," Society of Plastics Engineers, vol. 39, pp. 1-10, 2017.

[90] S. Shankar, Y. Bang, and J. Rhim, "Antibacterial LDPE/GSE/ $\mathrm{Mel} / \mathrm{ZnONP}$ composite film-coated wrapping paper for convenience food packaging application," Food Packaging and Shelf Life, vol. 22, pp. 1-9, 2019.

[91] J. Zia, U. C. Paul, J. A. Heredia-Guerrero, A. Athanassiou, and D. Fragouli, "Low-density polyethylene/curcumin melt extruded composites with enhanced water vapor barrier and antioxidant properties for active food packaging," Polymer, vol. 175, pp. 137-145, 2019.

[92] N. A. Abdelwahab and M. A. Abd El-Ghaffar, "Preparation, characterization, and evaluation of poly(p-azidoaniline) as thermal stabilizer for low density polyethylene films," Polymer-Plastics Technology and Engineering, vol. 55, no. 2, pp. 158-170, 2016.

[93] Z. Dong, F. Xu, I. Ahmed, Z. Li, and H. Lin, "Characterization and preservation performance of active polyethylene films containing rosemary and cinnamon essential oils for Pacific white shrimp packaging," Food Control, vol. 92, pp. 37-46, 2018.

[94] N. E. Zakaria, I. Ahmad, W. N. Wan Busu, K. H. Khalid, and A. Baharum, "Kesan penambahan kepingan nanozarah grafin terhadap sifat mekanik dan terma hibrid komposit 
serabut sansevieria-getah asli-polietilena berketumpatan tinggi," Sains Malaysiana, vol. 48, no. 5, pp. 1121-1128, 2019.

[95] Y. He, G. J. Fan, C. E. Wu et al., "Influence of packaging materials on postharvest physiology and texture of garlic cloves during refrigeration storage," Food Chemistry, vol. 298, pp. 125019-125028, 2019.

[96] H. M. Eyssa, S. G. Sawires, and M. M. Senna, "Gamma irradiation of polyethylene nanocomposites for food packaging applications against stored-product insect pests," Journal of Vinyl and Additive Technology, vol. 25, no. 1, pp. 1-10, 2018.

[97] S. Dixit and V. L. Yadav, "Optimization of polyethylene/ polypropylene/alkali modified wheat straw composites for packaging application using RSM," Journal of Cleaner Production, vol. 240, pp. 1-13, 2019.

[98] K. K. Gaikwad, S. Singh, J. Shin, and Y. Suk, "Novel polyisoprene based UV-activated oxygen scavenging films and their applications in packaging of beef jerky," LebensmittelWissenschaft und -Technologie- Food Science and Technology, vol. 117, pp. 1-9, 2020.

[99] A. Vidács, E. Kerekes, R. Rajkó et al., "Optimization of essential oil-based natural disinfectants against Listeria monocytogenes and Escherichia coli biofilms formed on polypropylene surfaces," Journal of Molecular Liquids, vol. 255, pp. 257-262, 2018.

[100] M. Llana-Ruiz-Cabello, S. Pichardo, J. M. Bermudez et al., "Characterization and antimicrobial activity of active polypropylene films containing Oregano essential oil and Allium extract to be used in packaging for meat products," Food Additives \& Contaminants: Part A, vol. 35, no. 4, pp. 782791, 2017.

[101] M.-J. Khalaj, H. Ahmadi, R. Lesankhosh, and G. Khalaj, "Study of physical and mechanical properties of polypropylene nanocomposites for food packaging application: nano-clay modified with iron nanoparticles," Trends in Food Science \& Technology, vol. 51, pp. 41-48, 2016.

[102] S. Singh, M. h. Lee, I. Park, Y. J. Shin, and Y. S. Lee, “Antimicrobial properties of polypropylene films containing $\mathrm{AgSiO} 2, \mathrm{AgZn}$ and $\mathrm{AgZ}$ for returnable packaging in seafood distribution," Journal of Food Measurement and Characterization, vol. 10, no. 4, pp. 781-793, 2016.

[103] R. Prabhu and A. Devaraju, "Developing an antimicrobial packaging to improve the shelf life of meat using silver zeolite coating on BOPP film," Materials Today Proceedings, vol. 5, no. 6, pp. 14553-14559, 2018.

[104] Y. Zhang, Y. Peng, R. Jia, Q. Wang, X. Lou, and J. Shi, "Sodium chloride combined with polypropylene film can maintain the quality of fresh-cut ginger," Food Packaging and Shelf Life, vol. 25, pp. 1-11, 2020.

[105] K. Lim, Y. Ching, and S. Gan, "Effect of palm oil bio-based plasticizer on the morphological, thermal and mechanical properties of poly(vinyl chloride)," Polymers, vol. 7, no. 10, pp. 2031-2043, 2015.

[106] B. Tarus, N. Fadel, A. Al-Oufy, and M. El-Messiry, "Effect of polymer concentration on the morphology and mechanical characteristics of electrospun cellulose acetate and poly(vinyl chloride) nanofiber mats," Alexandria Engineering Journal, vol. 55, no. 3, pp. 1-10, 2016.

[107] S. Azlin-Hasim, M. C. Cruz-Romero, M. A. Morris, S. C. Padmanabhan, E. Cummins, and J. P. Kerry, "The potential application of antimicrobial silver polyvinyl chloride nanocomposite films to extend the shelf-life of chicken breast fillets," Food and Bioprocess Technology, vol. 9, no. 10, pp. 1661-1673, 2016.
[108] M. Yadav, S. Ahmad, and F.-C. Chiu, "Graphene oxide dispersed polyvinyl chloride/alkyd green nanocomposite film: processing and physico-mechanical properties," Journal of Industrial and Engineering Chemistry, vol. 68, pp. 246-256, 2018.

[109] X. Zhang, L. Zhang, and A. Li, "Co-hydrothermal carbonization of lignocellulosic biomass and waste polyvinyl chloride for high-quality solid fuel production: hydrochar properties and its combustion and pyrolysis behaviors," Bioresource Technology, vol. 294, pp. 122113-122119, 2019.

[110] L. R. Braga, E. T. Rangel, P. Anselmo, Z. Suarez, and F. Machado, "Simple synthesis of active films based on PVC incorporated with silver nanoparticles: evaluation of the thermal, structural and antimicrobial properties," Food Packaging and Shelf Life, vol. 15, pp. 122-129, 2017.

[111] M. Chmiel, E. Hać-Szymańczuk, L. Adamczak, D. Pietrzak, T. Florowski, and A. Cegiełka, "Quality changes of chicken breast meat packaged in a normal and in a modified atmosphere," The Journal of Applied Poultry Research, vol. 27, no. 3, pp. 349-362, 2018.

[112] F. B. Foralosso, N. Fronza, J. H. Z. dos Santos, L. B. Capeletti, and M. G. N. Quadri, "The use of duo-functional PVC film for conservation of minimally processed apples," Food and Bioprocess Technology, vol. 7, no. 5, pp. 1483-1495, 2013.

[113] Z. Pilevar, A. Bahrami, S. Beikzadeh, H. Hosseini, and S. M. Jafari, "Migration of styrene monomer from polystyrene packaging materials into foods: characterization and safety evaluation," Trends in Food Science \& Technology, vol. 91, pp. 248-261, 2019.

[114] K. Kik, B. Bukowska, and P. Sicinska, "Polystyrene nanoparticles: sources, occurrence in the environment, distribution in tissues, accumulation and toxicity to various," Environmental Pollution, vol. 262, pp. 1-9, 2020.

[115] L. Abolghasemi Fakhri, B. Ghanbarzadeh, J. Dehghannya, F. Abbasi, and H. Ranjbar, "Optimization of mechanical and color properties of polystyrene/nanoclay/nano $\mathrm{ZnO}$ based nanocomposite packaging sheet using response surface methodology," Food Packaging and Shelf Life, vol. 17, pp. 11-24, 2018.

[116] Y. Yang, J. Yang, W.-M. Wu et al., "Biodegradation and mineralization of polystyrene by plastic-eating mealworms: Part 2. Role of gut microorganisms," Environmental Science and Technology, vol. 49, no. 20, pp. 12087-12093, 2015.

[117] S. Ibrahim, M. E. El-Naggar, A. M. Youssef, and M. S. AbdelAziz, "Functionalization of polystyrene nanocomposite with excellent antimicrobial efficiency for food packaging application," Journal of Cluster Science, vol. 31, no. 6, pp. 1371-1382, 2019.

[118] A. Eksirinimitr, E. Wimolmala, K. Taptim, and N. Sombatsompop, "Effects of simulation conditions on antibacterial performance of polypropylene and polystyrene doped with HPQM antibacterial agent," Polymer Testing, vol. 55, pp. 123-134, 2016.

[119] E.-S. A. Hegazy, A. M. A. Ghaffar, and H. E. Ali, "Characterization and radiation modification of low density polyethylene/polystyrene/maleic anhydride/magnesium hydroxide blend nanocomposite," Materials Chemistry and Physics, vol. 252, no. 1, pp. 1-10, 2020.

[120] V. Kouloumpis, R. S. Pell, M. E. Correa-Cano, and X. Yan, "Potential trade-offs between eliminating plastics and mitigating climate change: an LCA perspective on polyethylene terephthalate (PET) bottles in Cornwall," The Science of the Total Environment, vol. 727, pp. 138681-138710, 2020. 
[121] D.-J. Kim and K.-T. Lee, "Determination of monomers and oligomers in polyethylene terephthalate trays and bottles for food use by using high performance liquid chromatographyelectrospray ionization-mass spectrometry," Polymer Testing, vol. 31, no. 3, pp. 490-499, 2012.

[122] A. Gisario, F. Veniali, M. Barletta, V. Tagliaferri, and S. Vesco, "Laser transmission welding of poly(ethylene terephthalate) and biodegradable poly(ethylene terephthalate) - based blends," Optics and Lasers in Engineering, vol. 90, pp. 110-118, 2017.

[123] Y. Ding, Y. Jiang, Y. Deng, and Y. Zhao, "Effect of packaging materials and storage temperature on water status, mechanical and thermal properties of black garlic," Food Packaging and Shelf Life, vol. 24, no. 4, pp. 1-9, 2020.

[124] A. M. Giuffre, L. Louadj, P. Rizzo, M. Poiana, and V. Sicari, "Packaging and storage condition affect the physicochemical properties of red raspberries (Rubus idaeus L., cv. Erika)," Food Control, vol. 97, no. 3, pp. 105-113, 2018.

[125] K. Antonis, "Alterations of PET material physical properties during storage of olive oil," Food Packaging and Shelf Life, vol. 21, no. 807-810, pp. 1-7, 2019.

[126] F. Essabti, A. Guinault, S. Roland, G. Régnier, S. Ettaqi, and M. Gervais, "Preparation and characterization of poly(ethylene terephthalate) films coated by chitosan and vermiculite nanoclay," Carbohydrate Polymers, vol. 201, pp. 392-401, 2018.

[127] S. Ishtiaque, S. Naz, J. Ahmed, and A. Faruqui, "Barrier properties analysis of polyethylene terephthalate films (PET) coated with natural polyphenolic and gelatin mixture (PGM)," Defect and Diffusion Forum, vol. 382, pp. 38-43, 2018.

[128] M. I. C. Mohd Noh, M. A. Mohamed, A. G. Ismail, M. H. Ani, and B. Y. Majlis, "Improvement of gas barrier properties of polyethylene terephtalate (PET) by graphene nanoplatelets (GNP)," Materials Today Proceedings, vol. 7, pp. 808-815, 2019.

[129] S. Nayak and S. k. Khuntia, "Development and study of properties of Moringa oleifera fruit fibers/polyethylene terephthalate composites for packaging applications," Composites Communications, vol. 15, pp. 113-119, 2019.

[130] S. H. Fasihnia, S. H. Peighambardoust, S. J. Peighambardoust, and A. Oromiehie, "Development of novel active polypropylene based packaging films containing different concentrations of sorbic acid," Food Packaging and Shelf Life, vol. 18, pp. 87-94, 2018.

[131] H. Moustafa, A. E.-A. A. El-Wakil, M. T. Nour, and A. M. Youssef, "Kenaf fibre treatment and its impact on the static, dynamic, hydrophobicity and barrier properties of sustainable polystyrene biocomposites," RSC Advances, vol. 10, no. 49, pp. 29296-29305, 2020.

[132] D. K. Takma and F. Korel, "Active packaging films as a carrier of black cumin essential oil: development and effect on quality and shelf-life of chicken breast meat," Food Packaging and Shelf Life, vol. 19, pp. 210-217, 2018.

[133] A. Larranaga and E. Lizundia, "A review on the thermomechanical properties and biodegradation behaviour of polyesters," European Polymer Journal, vol. 121, pp. 1-59, 2019.

[134] M. del Rosario Salazar-Sánchez, S. D. Campo-Erazo, H. S. Villada-Castillo, J. F. Solanilla-Duque, and J. F. Solanilla-Duque, "Structural changes of cassava starch and polylactic acid films submitted to biodegradation process," International Journal of Biological Macromolecules, vol. 129, pp. 442-447, 2019.
[135] U. S. U. Kumar, M. T. Paridah, F. A. T. Owolabi et al., "Neem leaves extract based seaweed bio-degradable composite films with excellent antimicrobial activity for sustainable packaging material," Bioresources, vol. 14, no. 1, pp. 700-713, 2019.

[136] K. Shanmugam, H. Doosthosseini, S. Varanasi, G. Garnier, and W. Batchelor, "Nanocellulose films as air and water vapour barriers: a recyclable and biodegradable alternative to polyolefin packaging," Sustainable Materials and Technology, vol. 22, pp. 1-8, 2019.

[137] N. S. N. Mazlan, S. Zakaria, S. Gan, C. C. Hua, and K. W. Baharin, "Comparison of regenerated cellulose membrane coagulated in sulphate based coagulant," Cerne, vol. 25, no. 1, pp. 18-24, 2019.

[138] S. Thambiraj and D. R. Shankaran, "Preparation and physicochemical characterization of cellulose nanocrystals from industrial waste cotton," Applied Surface Science, vol. 412, pp. 1-37, 2017.

[139] H. Wu, C. Teng, B. Liu, H. Tian, and J. Wang, "Characterization and long term antimicrobial activity of the nisin anchored cellulose films," International Journal of Biological Macromolecules, vol. 113, pp. 487-493, 2018.

[140] A. A. A. Alim and R. Othaman, "Epoxidized natural rubber/ polyvinyl chloride/microcrystalline cellulose (ENR/PVC/ MCC) composite membrane for palm oil mill effluent (POME) treatment," Sains Malaysiana, vol. 47, no. 7, pp. 1517-1525, 2018.

[141] B. Bideau, J. Bras, N. Adoui, E. Loranger, and C. Daneault, "Polypyrrole/nanocellulose composite for food preservation: barrier and antioxidant characterization," Food Packaging and Shelf Life, vol. 12, pp. 1-8, 2017.

[142] M. E. Achaby, N. E. Miri, A. Aboulkas et al., "Processing and properties of eco-friendly bio- nanocomposite films filled with cellulose nanocrystals from sugarcane bagasse," International Journal of Biological Macromolecules, vol. 96, pp. 340-352, 2016.

[143] C. López de Dicastillo, F. Bustos, A. Guarda, and M. J. Galotto, "Cross-linked methyl cellulose films with murta fruit extract for antioxidant and antimicrobial active food packaging," Food Hydrocolloids, vol. 60, pp. 335-344, 2016.

[144] C. Liu, J. Huang, X. Zheng et al., "Heat sealable soluble soybean polysaccharide/gelatin blend edible films for food packaging applications," Food Packaging and Shelf Life, vol. 24, pp. 1-9, 2020.

[145] M. S. P. Abdullah, M. I. Noordin, S. I. M. Ismail et al., "Recent advances in the use of animal-sourced gelatine as natural polymers for food, cosmetics and pharmaceutical applications," Sains Malaysiana, vol. 47, no. 2, pp. 323-336, 2018.

[146] Y. Ge, Y. Li, Y. Bai, C. Yuan, C. Wu, and Y. Hu, "Intelligent gelatin/oxidized chitin nanocrystals nanocomposite films containing black rice bran anthocyanins for fish freshness monitorings," International Journal of Biological Macromolecules, vol. 155, pp. 1-36, 2019.

[147] R. Battisti, N. Fronza, Á. Vargas Júnior, S. M. d. Silveira, M. S. P. Damas, and M. G. N. Quadri, "Gelatin-coated paper with antimicrobial and antioxidant effect for beef packaging," Food Packaging and Shelf Life, vol. 11, pp. 115-124, 2017.

[148] T. de Moraes Crizel, A. de Oliveira Rios, V. Alves, N. Bandarra, M. Moldão-Martins, and S. Hickmann Flôres, "Biodegradable films based on gelatin and papaya peel 
microparticles with antioxidant properties," Food and Bioprocess Technology, vol. 11, no. 3, pp. 536-550, 2017.

[149] S. Soradech, J. Nunthanid, S. Limmatvapirat, and M. Luangtana-Anan, "Utilization of shellac and gelatin composite film for coating to extend the shelf life of banana," Food Control, vol. 73, pp. 1310-1317, 2017.

[150] M. A. Oliveira, R. F. Furtado, M. S. R. Bastos et al., "Performance evaluation of cashew gum and gelatin blend for food packaging," Food Packaging and Shelf Life, vol. 17, pp. 57-64, 2018.

[151] T. Huang, Z. Fang, H. Zhao et al., "Physical properties and release kinetics of electron beam irradiated fish gelatin films with antioxidants of bamboo leaves," Food Bioscience, vol. 36, pp. 1-39, 2020.

[152] J. J. Koh, X. Zhang, and C. He, "Fully biodegradable pol$\mathrm{y}$ (lactic acid)/starch blends: a review of toughening strategies," International Journal of Biological Macromolecules, vol. 109, pp. 99-113, 2018.

[153] M. P. Arrieta, L. Peponi, D. López, and M. Fernández-García, "Recovery of yerba mate (Ilex paraguariensis) residue for the development of PLA-based bionanocomposite films," Industrial Crops and Products, vol. 111, pp. 317-328, 2018.

[154] A. Khosravi, A. Fereidoon, M. M. Khorasani et al., "Soft and hard sections from cellulose-reinforced poly(lactic acid)based food packaging films: a critical review," Food Packaging and Shelf Life, vol. 23, no. 100429, pp. 1-17, 2020.

[155] M. Zorah, I. R. Mustapa, N. Daud et al., "Improvement thermomechanical properties of polylactic acid via titania nanofillers reinforcement," Journal of Advanced Research in Fluid Mechanics and Thermal Sciences, vol. 70, no. 1, pp. 97-111, 2020.

[156] M. M. Rahman, M. S. Islam, and G. S. Li, "Development of $\mathrm{PLA} / \mathrm{CS} / \mathrm{ZnO}$ nanocomposites and optimization its mechanical, thermal and water absorption properties," Polymer Testing, vol. 68, pp. 302-308, 2018.

[157] S. Sharma, A. K. Jaiswal, B. Duffy, and S. Jaiswal, "Ferulic acid incorporated active films based on poly(lactide)/pol$\mathrm{y}$ (butylene adipate-co-terephthalate) blend for food packaging," Food Packaging and Shelf Life, vol. 24, no. 100491, pp. 1-7, 2020.

[158] C. Swaroop and M. Shukla, "Nano-magnesium oxide reinforced polylactic acid biofilms for food packaging applications," International Journal of Biological Macromolecules, vol. 113, pp. 729-736, 2018.

[159] Z. Chu, T. Zhao, L. Li, J. Fan, and Y. Qin, "Characterization of antimicrobial poly (lactic acid)/nano-composite films with silver and zinc oxide nanoparticles," Materials, vol. 10, no. 6, pp. 1-13, 2017.

[160] A. Altan, Z. Aytac, and T. Uyar, "Carvacrol loaded electrospun fibrous films from zein and poly(lactic acid) for active food packaging," Food Hydrocolloids, vol. 81, pp. 4859, 2018.

[161] R. D. Kale, V. G. Gorade, N. Madye, B. Chaudhary, P. S. Bangde, and P. P. Dandekar, "Preparation and characterization of biocomposite packaging film from poly(lactic acid) and acylated microcrystalline cellulose using rice bran oil," International Journal of Biological Macromolecules, vol. 118, pp. 1090-1102, 2018.

[162] C. Villegas, M. P. Arrieta, A. Rojas et al., "PLA/organoclay bionanocomposites impregnated with thymol and cinnamaldehyde by supercritical impregnation for active and sustainable food packaging," Composites Part B, vol. 176, pp. 1-12, 2019.
[163] M. Rezaeigolestani, A. Misaghi, A. Khanjari, A. A. Basti, A. Abdulkhani, and S. Fayazfar, "Antimicrobial evaluation of novel poly-lactic acid based nanocomposites incorporated with bioactive compounds in-vitro and in refrigerated vacuum-packed cooked sausages," International Journal of Food Microbiology, vol. 260, pp. 1-10, 2017.

[164] N. Mlalila, A. Hilonga, H. Swai, F. Devlieghere, and P. Ragaert, "Antimicrobial packaging based on starch, poly(3-hydroxybutyrate) and poly(lactic-co-glycolide) materials and application challenges," Trends in Food Science \& Technology, vol. 74, pp. 1-11, 2018.

[165] K. A. Garrido-Miranda, B. L. Rivas, M. A. Perez, E. A. Sanfuentes, and C. Pena-Farfal, "Antioxidant and antifungal effects of eugenol incorporated in bionanocomposites of poly-(3-hydroxybutyrate)-thermoplastic starch," Lebensmittel-Wissenschaft und -Technologie- Food Science and Technology, vol. 98, pp. 1-21, 2018.

[166] A. Cherpinski, M. Gozutok, H. T. Sasmazel, S. Torres-Giner, and J. M. Lagaron, "Electrospun oxygen scavenging films of poly(3-hydroxybutyrate) containing palladium nanoparticles for active packaging applications," Nanomaterials, vol. 8, no. 7, pp. 1-19, 2018.

[167] A. D. Tripathi, T. Raj Joshi, S. Kumar Srivastava, K. K. Darani, S. Khade, and J. Srivastava, "Effect of nutritional supplements on bio-plastics (PHB) production utilizing sugar refinery waste with potential application in food packaging," Preparative Biochemistry \& Biotechnology, vol. 49, no. 6, pp. 567-577, 2019.

[168] N. A. Manikandan, K. Pakshirajan, and G. Pugazhenthi, "Preparation and characterization of environmentally safe and highly biodegradable microbial polyhydroxybutyrate (PHB) based graphene nanocomposites for potential food packaging applications," International Journal of Biological Macromolecules, vol. 154, pp. 866-877, 2020.

[169] Y. Ma, L. Li, and W. Yifen, "Development of PLA- PHBbased biodegradable active packaging and its application to salmon," Packaging Technology and Science, vol. 31, no. 11, pp. 1-8, 2018.

[170] X. Zhao, K. Ji, K. Kurt, K. Cornish, and Y. Vodovotz, "Optimal mechanical properties of biodegradable natural rubber-toughened PHBV bioplastics intended for food packaging applications," Food Packaging and Shelf Life, vol. 21 , pp. 1-11, 2019

[171] J. Xie and Y.-C. Hung, "UV-A activated TiO2 embedded biodegradable polymer film for antimicrobial food packaging application," Lebensmittel-Wissenschaft \& Technologie, vol. 96, pp. 307-314, 2018.

[172] D. R. M. Andrade, S. M. Junior Silver da, S. V. C. R. Coutinho et al., "PCL/ZnO bio-friendly films as food packaging material. thermal and morphological analysis," Revista materia, vol. 23, no. 4, pp. 1-10, 2018.

[173] S. Khalid, L. Yu, M. Feng et al., "Development and characterization of biodegradable antimicrobial packaging films based on polycaprolactone, starch and pomegranate rind hybrids," Food Packaging and Shelf Life, vol. 18, pp. 71-79, 2018.

[174] F. Benhacine, A. Ouargli, and A. S. Hadj-Hamou, "Preparation and characterization of novel food packaging materials based on biodegradable PCL/Ag-kaolinite nanocomposites with controlled release properties," Polymer-Plastics Technology and Engineering, vol. 58, no. 3, pp. 1-13, 2018.

[175] L. R. Mugwagwa and A. F. A. Chimphango, "Enhancing the functional properties of acetylated hemicellulose films for 
active food packaging using acetylated nanocellulose reinforcement and polycaprolactone coating," Food Packaging and Shelf Life, vol. 24, pp. 1-10, 2020.

[176] J. Ahmed, M. Mulla, H. Jacob, G. Luciano, and T. B. Bini, "Polylactide/poly( $\varepsilon$-caprolactone)/zinc oxide/clove essential oil composite antimicrobial films for scrambled egg packaging," Food Packaging and Shelf Life, vol. 21, pp. 1-9, 2019.

[177] K. J. Figueroa-Lopez, J. L. Castro-Mayorga, M. M. AndradeMahecha, L. Cabedo, and J. M. Lagaron, "Antibacterial and barrier properties of gelatin coated by electrospun polycaprolactone ultrathin fibers containing black pepper oleoresin of interest in active food biopackaging applications," Nanomaterials, vol. 8, no. 4, pp. 1-13, 2018.

[178] K. Wang, P. N. Lim, S. Y. Tong, and E. S. Thian, "Development of grapefruit seed extract-loaded poly( $\varepsilon$-caprolactone)/chitosan films for antimicrobial food packaging," Food Packaging and Shelf Life, vol. 22, pp. 1-8, 2019.

[179] G. Santagata, F. Valerio, A. Cimmino et al., "ChemicoPhysical and antifungal properties of poly(butylene succinate)/cavoxin blend: study of a novel bioactive polymeric based system," European Polymer Journal, vol. 94, pp. 230247, 2017.

[180] R. S. Ayu, A. Khalina, A. S. Harmaen et al., "Effect of empty fruit brunch reinforcement in PolyButylene-succinate/ modified tapioca starch blend for agricultural mulch films," Scientific Reports, vol. 10, pp. 1166-1167, 2020.

[181] S. Vytejckova, L. Vapenka, J. Hradecky et al., "Testing of polybutylene succinate based films for poultry meat packaging," Polymer Testing, vol. 60, pp. 357-364, 2017.

[182] Y. Zhang, S. Zhou, X. Fang et al., "Renewable and flexible UV-blocking film from poly(butylene succinate) and lignin," European Polymer Journal, vol. 116, pp. 265-274, 2019.

[183] R. S. Ayu, A. Khalina, A. S. Harmaen, K. Zaman, M. Jawaid, and C. H. Lee, "Effect of modified tapioca starch on mechanical, thermal, and morphological properties of PBS blends for food packaging," Polymers, vol. 10, no. 11, pp. 1-13, 2018.

[184] N. Wattanawong, K. Chatchaipaiboon, N. Sreekirin, and D. Aht-Ong, "Migration, physical and antibacterial properties of silver zeolite/poly(butylene succinate) composite films for food packaging applications," Journal of Reinforced Plastics and Composites, vol. 39, no. 3-4, pp. 1-16, 2019.

[185] N. Petchwattana and P. Naknaen, "Utilization of thymol as an antimicrobial agent for biodegradable poly(butylene succinate)," Materials Chemistry and Physics, vol. 163, pp. 369-375, 2015.

[186] M. Negrin, E. Macerata, G. Consolati et al., "Gamma radiation effects on random copolymers based on poly(butylene succinate) for packaging applications," Radiation Physics and Chemistry, vol. 142, pp. 34-43, 2017.

[187] S. N. Syahida, M. R. Ismail-Fitry, Z. M. A. Ainun, and Z. A. N. Hanani, "Effects of palm wax on the physical, mechanical and water barrier properties of fish gelatin films for food packaging application," Food Packaging and Shelf Life, vol. 23, pp. 1-9, 2020.

[188] P. E. Fathima, S. K. Panda, P. M. Ashraf, T. O. Varghese, and J. Bindu, "Polylactic acid/chitosan films for packaging of Indian white prawn (Fenneropenaeus indicus)," International Journal of Biological Macromolecules, vol. 117, pp. 1002-1010, 2017.

[189] L. Miao, W. C. Walton, L. Wang, L. Li, and Y. Wang, "Characterization of polylactic acids-polyhydroxybutyrate based packaging film with fennel oil, and its application on oysters," Food Packaging and Shelf Life, vol. 22, pp. 1-8, 2019.
[190] E. L. Sánchez-Safont, A. Aldureid, J. M. Lagarón, J. GámezPérez, and L. Cabedo, "Biocomposites of different lignocellulosic wastes for sustainable food packaging applications," Composites Part B: Engineering, vol. 145, pp. 215-225, 2018.

[191] A. H. Ardekani-Zadeh and S. F. Hosseini, "Electrospun essential oil-doped chitosan/poly( $\varepsilon$-caprolactone) hybrid nanofibrous mats for antimicrobial food biopackaging exploits," Carbohydrate Polymers, vol. 223, pp. 1-10, 2019.

[192] M. I. Perdana, J. Ruamcharoen, S. Panphon, and M. Leelakriangsak, "Antimicrobial activity and physical properties of starch/chitosan film incorporated with lemongrass essential oil and its application," LWT-Food and Science Technology, vol. 141, pp. 1-8, 2021.

[193] L. M. Junior, da R. G. Silva, C. A. R. Anjos, R. P. Vieira, and R. M. V. ( Alves, "Effect of low concentrations of $\mathrm{SiO} 2$ nanoparticles on the physical and chemical properties of sodium alginate-based films," Carbohydrate Polymers, vol. 269, pp. 1-7, 2021.

[194] V. V. T. Padil, C. Senan, S. Wacławek, M. Černík, S. Agarwal, and R. S. Varma, "Bioplastic fibers from gum Arabic for greener food wrapping applications," ACS Sustainable Chemistry \& Engineering, vol. 7, no. 6, pp. 5900-5911, 2019.

[195] P. Terzioglu, F. Guney, F. N. Parin, I. Sen, and S. Tuna, "Biowaste orange peel incorporated chitosan/polyvinyl alcohol composite films for food packaging applications," Food Packaging and Shelf Life, vol. 30, pp. 1-12, 2021. 